\title{
Calidad botánica de drogas crudas comercializadas como "canchalagua" en Córdoba, Argentina
}

\author{
MARÍA L. MOLINELLI'1 PATRICIA PERISSÉ1 ${ }^{1}$ ELSA FUENTES ${ }^{1}$ y ANA M. PLANCHUELO ${ }^{1,2}$
}

\begin{abstract}
Summary: Botanical quality of herbal drugs marketed as "canchalagua" in Córdoba, Argentina. Evaluation of morpho-anatomical characters of medicinal plants marketed as herbal drugs under the vernacular name of "canchalagua", were done in samples acquired in stores located in the cities of Córdoba (State Capital), Alta Gracia (Santa María County), Villa General Belgrano and Santa Rosa de Calamuchita (Calamuchita County) to verify the quality of the medicinal products. The taxa found in each one of the 59 samples were identified by morpho-anatomical studies of leaves, stems, flowers and fruits using several plant histological techniques. The results showed that Schkuhria pinnata (Asteraceae), Scoparia montevidensis (Plantaginaceae) and a mix of both species are sold as pure drug of "canchalagua". Also, Parthenium hysterophorus L. (Asteraceae) was identified as an adulterant of S. pinnata. A quality control showed that some samples did not meet the standards of botanical identity because they had either several species mixed or adulteration and falsifications with other species, which were not related to "canchalagua". This study provides a set of morpho-anatomical and diagnostic characters to establish the botanical quality of the "canchalagua" herbal drug.
\end{abstract}

Keywords: Morpho-anatomical characters, quality control, Schkuhria pinnata, Scoparia montevidensis, Parthenium hysterophorus, canchalagua.

\begin{abstract}
Resumen: El objetivo de este trabajo fue identificar las especies, aportar caracteres morfo-anatómicos de valor diagnóstico y establecer la legitimidad de las drogas crudas que se expenden bajo el nombre de "canchalagua". Se analizaron 59 muestras de drogas compradas en comercios de la ciudad de Córdoba (Departamento Capital), Alta Gracia (Departamento Santa María), Villa General Belgrano y Santa Rosa de Calamuchita (Departamento Calamuchita) rotuladas con el nombre de "canchalagua". Se determinaron los taxones que componían cada una de las muestras y se realizaron estudios morfo-anatómicos de las hojas, tallos, flores y frutos encontrados, empleando distintas técnicas de histología vegetal. Los resultados demostraron que se expenden como droga pura de "canchalagua" Scoparia montevidensis (Plantaginaceae), Schkuria pinnata (Asteraceae) y las mezclas de ambas. Se identificó también a Parthenium hysterophorus (Asteraceae) como adulterante de Schkuria pinnata. La evaluación de calidad demostró la presencia de mezclas de especies, adulteraciones y falsificaciones, correspondiendo estos casos a muestras que no reúnen los requisitos de calidad botánica para su comercialización. Las caracterizaciones morfo-anatómicas de hojas, flores y frutos presentadas en este trabajo, aportan información de valor diagnóstico para los controles de calidad botánico de las muestras de "canchalagua".
\end{abstract}

Palabras clave: Caracteres morfo-anatómicos, control de calidad, Schkuhria pinnata, Scoparia montevidensis, Parthenium hysterophorus, canchalagua.

\footnotetext{
${ }^{1}$ Herbario ACOR. Facultad de Ciencias Agropecuarias. Universidad Nacional de Córdoba. 5000. Córdoba. Argentina. E-mail: mlmolinelli@agro.unc.edu.ar

${ }^{2}$ CREAN-CONICET. Facultad de Ciencias Agropecuarias. Universidad Nacional de Córdoba. 5000. Córdoba. Argentina.
} 


\section{INTRODUCCIÓN}

Las especies Scoparia montevidensis (Spreng.) R.E.Fr. (Plantaginaceae) y Schkuhria pinnata (Lam.) Kuntze ex Thell. (Asteraceae) son usadas en la medicina tradicional para el tratamiento de diversas afecciones de la salud y reconocidas con el nombre vernáculo de "canchalagua". Las características botánico-morfológicas de estas especies se encuentran descriptas en la Flora Medicinal de la Provincia de Córdoba (Barboza et al., 2006); mientras que los caracteres anatómicos de las familias a las que pertenecen (Plantaginaceae y Asteraceae) están descriptos e ilustrados en los tratados de Metcalfe \& Chalk (1972 y 1979).

Scoparia montevidensis, que es conocida además por los nombres vernáculos de "copita", "inambúcaá", "nambú-caá" o "hiel de tierra", se emplea como emenagoga, vulneraria, hepática, anticefálica, antidiarreica, hipolipemiante, para el tratamiento de infecciones urinarias y respiratorias y para el control de ectoparásitos (Toursarkissian, 1980; Del Vitto et al., 1997; Marzocca, 1997; Schulz, 1997; Menseguez et al., 2007; Barboza et al., 2009; Martínez, 2010), sin que medie un conocimiento fehaciente de la composición química y la actividad farmacológica de esta droga vegetal.

Por otro lado, para Schkuhria pinnata, también se citan los nombres vernáculos de "canchalahua", "manzanilla silvestre", "yerba de la pulga", "mata pulgas", "matapulga" o "matapulgas" (Marzocca, 1997; Petenatti \& Ariza Espinar, 1997; Núñez \& Cantero, 2000; Barboza et al., 2006; Arias Toledo, 2009). La medicina tradicional le atribuye propiedades como hepática, diurética, depurativa, adelgazante, antidiabética, antiinflamatoria, antibiótico, insecticida doméstico y para el tratamiento de infecciones urinarias (Ratera \& Ratera, 1980; Toursarkissian, 1980; Zardini, 1984; Del Vitto et al., 1997; Roig, 2001; Alonso \& Desmarchelier, 2006; Menseguez et al., 2007; Barboza et al., 2009; Arias Toledo, 2009; Martínez, 2010). Su empleo para el tratamiento de afecciones de origen dérmico como el acné y para las infecciones urinarias, así como sus usos como antimalárica, antimicrobiana y antioxidante están avalados por resultados de investigaciones farmacológicas (Gupta, 1995; Muñoz et al., 2000; Zampini et al., 2007; Bussmann et al., 2008 a y b; León et al., 2009). En relación a los constituyentes químicos se caracterizaron flavonoides, lactonas sesquiterpénicas y acil-fenilpropanoides en las partes aéreas de la planta (Mendiondo et al., 1990; Ganzer \& Jakupovic, 1990; Pacciaroni et al., 1995; León et al., 2009). La evaluación de la toxicidad de los componentes químicos mediante análisis de electroforesis de una sola célula, con la infusión de Schkuhria pinnata, evidenció daño genotóxico en el ADN de muestras de sangre humana (Gadano et al., 2004).

Cabe destacar que la falta de información sobre la composición química de las plantas medicinales, las contraindicaciones y los problemas de toxicidad que puedan presentar, así como las confusiones causadas por el uso de numerosos nombres vernáculos, son aspectos que deben ser investigados para garantizar el uso de las especies en la medicina tradicional (Croom, 1983; Balick et al., 2000; Cuassolo et al., 2009). Además, es importante contribuir con el control de calidad de las hierbas medicinales según lo establecido por la Organización Mundial de la Salud (2003).

Está ampliamente documentado que mediante la evaluación de los caracteres morfo-anatómicos se logra la identificación taxonómica de las especies medicinales presentes en los productos comerciales de droga cruda y que este procedimiento es indispensable para el control de calidad ya que permite detectar y determinar sustitutos y adulterantes (González-Tejero \& Casares-Porcel, 1996; Arenas, 2006; Vignale, 2007; Pochettino et al., 2008).

Teniendo en cuenta que Scoparia montevidensis y Schkuhria pinnata no se encuentran codificadas en la Farmacopea Nacional Argentina (1978) y que se comercializan como droga cruda bajo el mismo nombre vernáculo (Correa, 2003; Martínez, 2005; Luján \& Barboza, 2008; Hurrell et al., 2011), el objetivo de este trabajo es identificar las especies presentes en muestras comerciales que se expenden con el nombre de "canchalagua", aportar caracteres morfo-anatómicos de valor diagnóstico que permitan el reconocimiento de las especies identificadas y establecer la legitimidad de las drogas comercializadas.

\section{Materiales y Métodos}

Se analizaron 59 muestras de drogas adquiridas 
bajo el nombre vernáculo de "canchalagua", en comercios de la ciudad de Córdoba (Departamento Capital) y de las localidades serranas de Alta Gracia (Departamento Santa María), Villa General Belgrano y Santa Rosa de Calamuchita (Departamento Calamuchita). A su vez, se recolectaron plantas de Scoparia montevidensis y Schkuhria pinnata que fueron herborizadas, catalogadas (Herbario de A.M. Planchuelo), identificadas mediante bibliografía especializada (Cabrera, 1974; Botta \& Cabrera, 1993; Petenatti \& Ariza Espinar, 1997; Barboza et al., 2006) y depositadas en el herbario ACOR. Los ejemplares de herbario catalogados de Scoparia montevidensis (Spreng.) R. E. Fr. (AMP 2113 y 2656); Schkuhria pinnata (Lam.) Kuntze ex Thell. (AMP 1852 y 2660) y Parthenium hysterophorus L.(AMP 1892 y 2032), junto con los ejemplares conservados en F.A.A., sirvieron para contar con un patrón referencial que permitió verificar la identidad taxonómica de las estructuras vegetativas y reproductivas presentes en las muestras de las drogas adquiridas y determinar los caracteres morfo-anatómicos de valor diagnóstico de dichas especies.

Para la caracterización de las drogas analizadas de "canchalagua" se describieron las estructuras que las componen, el aspecto general y el color utilizando la carta de colores Munsell (2000).

Se efectuaron extracciones de epidermis y cortes anatómicos de las distintas estructuras encontradas, se colorearon con safranina-azul astral y se realizaron preparados permanentes y semi-permanentes. Las pruebas histoquímicas se efectuaron en cortes de material fresco mediante el uso de Lugol para confirmar la presencia de almidón y ácido nítrico para cristales ( $\mathrm{D}^{\prime}$ Ambrogio de Argüeso, 1986; Metclafe \& Chalk, 1989). Las observaciones se realizaron con la ayuda de microscopios estereoscópico y óptico, y se tomaron registros fotográficos. La terminología empleada se corresponde con la de Metcalfe \& Chalk (1972, 1979).

Para determinar el grado de legitimidad de las muestras se estableció una clasificación de acuerdo a los conceptos empleados por Nuñez (1975), Tyler Varro (1979), Creus (1986), Luján et al. (2000), Mitra \& Kannan (2007), Luján \& Barboza (2008), Código Alimentario Argentino (2009) y se consideró el nombre científico y vernáculo presente en los rótulos de las muestras analizadas.
Las drogas fueron clasificadas como: genuina, cuando la especie identificada se corresponde con el nombre científico declarado en el rótulo, o con el nombre vulgar cuando solamente este último figuraba en el rótulo; se consideró como droga falsificada a aquélla en la cual el nombre científico declarado en el rótulo no coincidía con el de la especie identificada; droga mezcla, a la muestra constituida por más de una droga genuina; droga adulterada, cuando la droga genuina se encontró reemplazada parcialmente por otra especie.

\section{Resultados y Discusión}

Especies presentes en muestras comerciales que se expenden con el nombre de "canchalagua"

Del análisis de las características macro y microscópicas de las 59 muestras de droga de "canchalagua" analizadas, se encontró que 30 muestras presentaron fragmentos de hojas, tallos, flores y frutos de Scoparia montevidensis; 22 de Schkuhria pinnata y 7 contenían una mezcla de estructuras pertenecientes a ambas especies. En 11 muestras se detectó además la presencia de estructuras vegetativas y reproductivas de Parthenium hysterophorus L. (Asteraceae) como adulterante.

Estos resultados demuestran que tanto Scoparia montevidensis como Schkuhria pinnata son especies medicinales comercializadas bajo el nombre vernáculo de "canchalagua" y concuerdan con lo señalado por Correa (2003).

Se debe destacar que a diferencia de lo enunciado por Hurrell et al. (2011), sobre el comercio de "canchalagua" en Buenos Aires y otras ciudades del país, los resultados de este trabajo evidencian que Scoparia montevidensis se comercializa con mayor frecuencia que Schkuhria pinnata, ya que tanto en las muestras adquiridas en la ciudad de Córdoba como en las localidades serranas existe un predomino de Scoparia montevidensis respecto a Schkuhria pinnata, siendo estas diferencias más evidentes en las localidades serranas (Fig. 1). Este resultado se puede explicar si se considera que en las localidades serranas del Departamento Santa María, sólo Scoparia montevidensis es recolectada por los campesinos de la región y expendida como "canchalagua" en los comercios de las sierras (Martínez, 2005). 


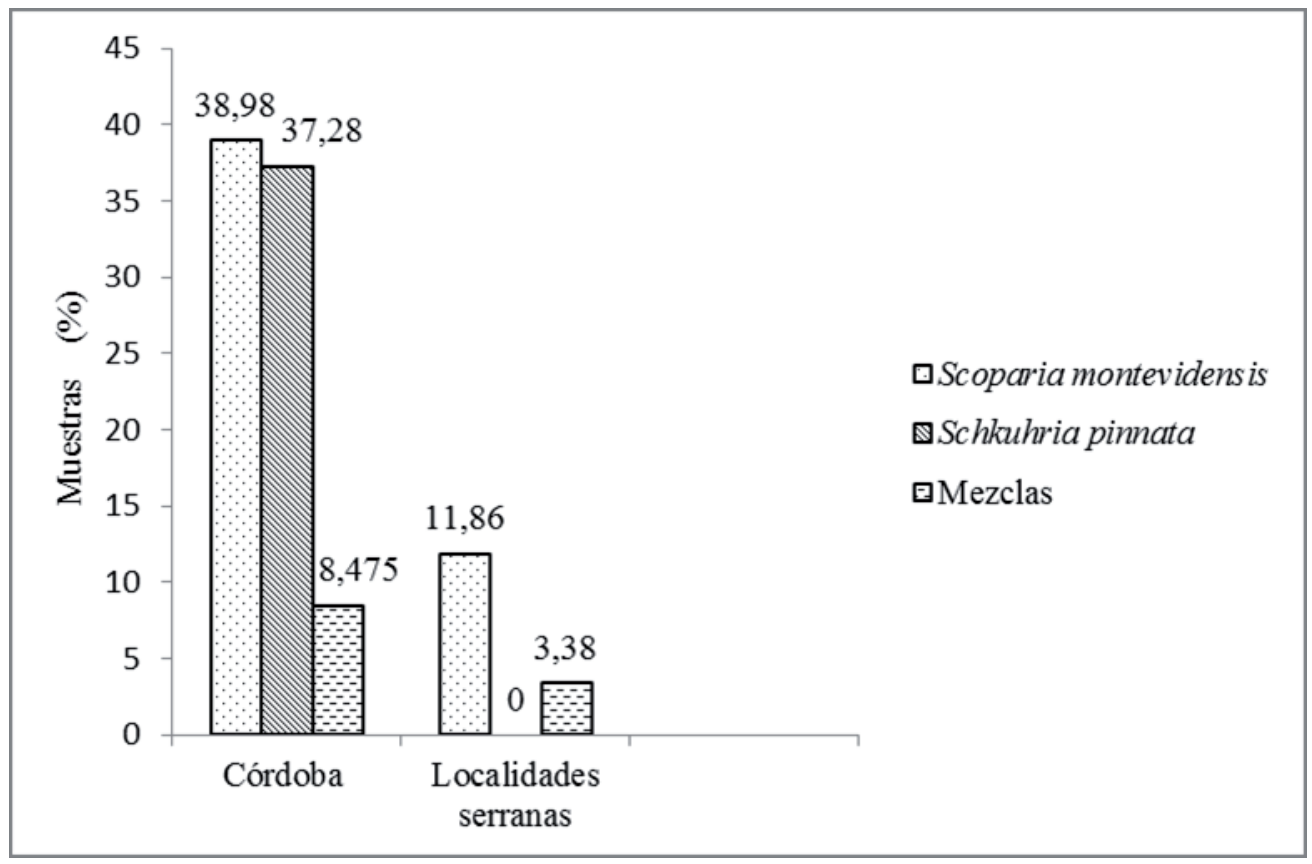

Fig.1. Porcentajes de Scoparia montevidensis y Schkuhria pinnata en muestras de "canchalagua" de la ciudad de Córdoba y de localidades serranas.

Caracteres morfo-anatómicos de valor diagnóstico que permiten el reconocimiento de las especies identificadas

\section{Scoparia montevidensis (Spreng.) R.E.Fr.}

La droga comprende toda la parte aérea de la planta. Las muestras comerciales presentaron el material cortado $(0,5 \mathrm{~cm}$ hasta $3 \mathrm{~cm})$, triturado (menos de $0,5 \mathrm{~cm}$ ) y sólo en unas pocas muestras se exhibía entero, con un color general marrón oliva claro 2.5 Y (5/4) (Fig. 2 A). Se observaron: fragmentos de tallos de color marrón oliva, hexagonales con 6 costillas y valles (Fig. 2 B), con hojas dispuestas en verticilos, estas últimas de color verde oscuro, lineares o lanceoladas con profundas incisiones (Fig. $2 \mathrm{C}$ ); flores anaranjado oscuro con pedúnculo, tetrámeras, perfectas y completas, con cáliz pentapartido y corola tetralobada (Fig. 2 D) con una corona de pelos en el interior, androceo con 4 estambres y gineceo con ovario glabro y un estilo alargado y dilatado en el ápice; cápsulas marrones, en su mayoría sueltas (Fig. $2 \mathrm{E}$ ), con cáliz persistente y pedúnculo glanduloso-pubescente.
Hoja. La epidermis foliar en vista superficial, se caracteriza por presentar las células fundamentales tanto en la superficie adaxial como abaxial con paredes anticlinales sinuosas (Fig. 3 A). El indumento es glanduloso-pubescente y presenta papilas de diferentes tamaños, levemente redondeadas, con cutícula estriada (Fig. 3 B) y ubicadas principalmente en los márgenes foliares, donde adquieren mayor altura. Los estomas son anomocíticos y hemiparacíticos (Fig. 3 C, D) en ambas epidermis. Los tricomas glandulares, más abundantes en la base foliar y sobre los nervios, presentan las siguientes variantes:

- Con pie 1-celular corto, presentan una célula basal y cabeza glandular globosa uni- a pluricelular (4-7 células) de paredes lisas. Estos tricomas se encuentran ubicados en depresiones (Fig. 3 E, F) y las células epidérmicas que los rodean se disponen radialmente.

- Con pie 2-4 celular, largo y uniseriado, la cabeza es glandular globosa o elipsoide (Fig. 4 A, B) y bicelular. Apoyados sobre una célula basal (cojinete de paredes gruesas) y en algunos tricomas la célula basal se encuentra sobre elevada de las restantes células epidérmicas. 


\section{L. Molinelli et al. - Calidad Botánica de las "Canchalaguas"}
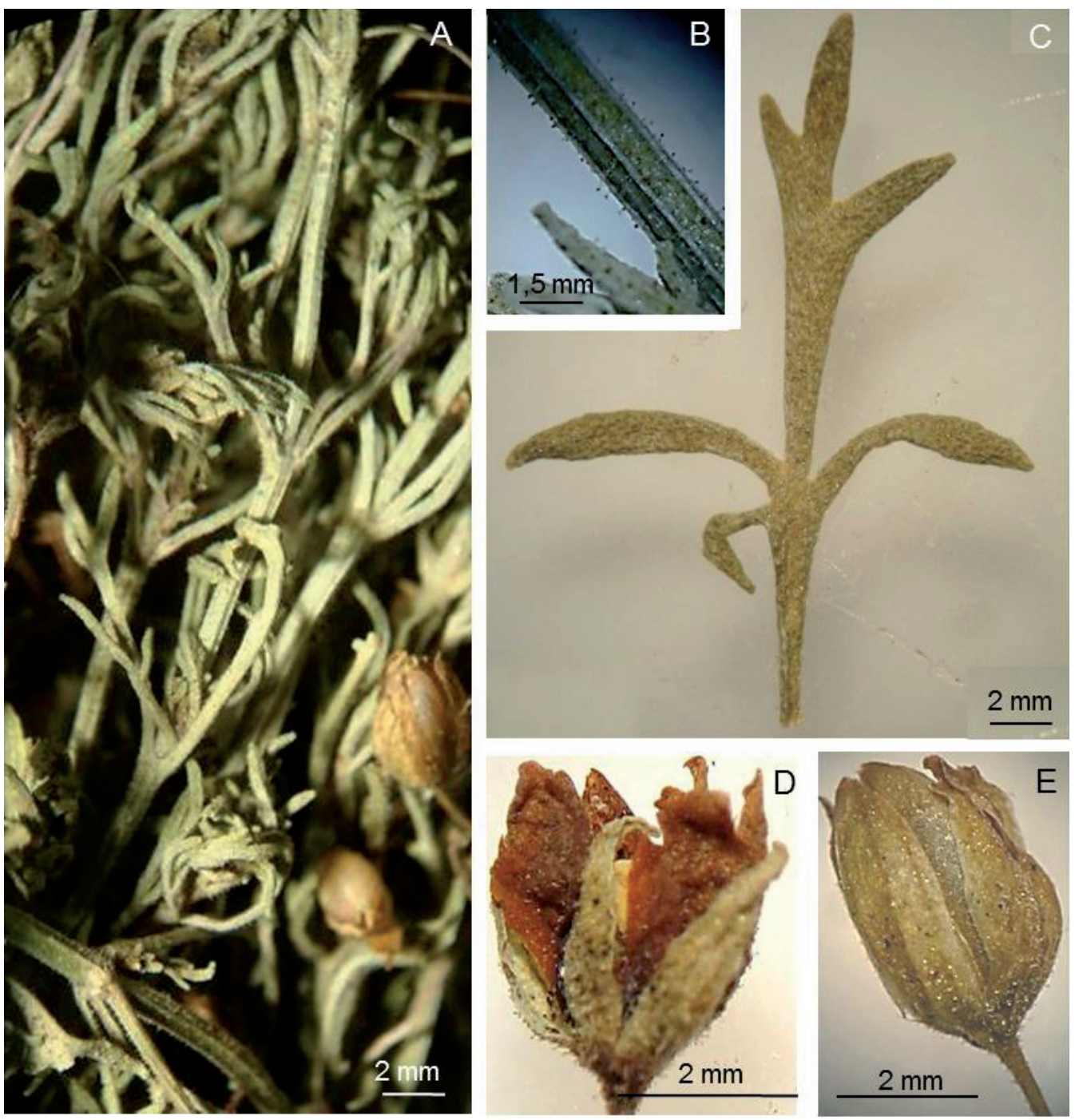

Fig. 2. Droga de Scoparia montevidensis. A: Tallos con hojas y frutos. B: Tallo y hojas con tricomas glandulares. C: Hoja, cara adaxial. D: Flor completa. E: Cápsula con sépalos y pedúnculo glandulosopubescente.

Las características de los tricomas coinciden en términos generales por lo descripto para la familia por Metcalfe \& Chalk (1972).

La lámina en transcorte posee contorno levemente angular con depresiones que le dan aspecto foveolado. La epidermis uniestrata con cutícula delgada está compuesta por células de tamaño y forma irregular. Los estomas se encuentran a nivel, levemente elevados, poseen una pequeña proyección a modo de uña en la cara externa de las células oclusivas y cámara subestomática pequeña. El mesofilo es dorsiventral (Fig. 4 D). El parénquima en empalizada está constituido por 3-4 estratos compactos de células rectangulares hacia la superficie adaxial, y el parénquima esponjoso, por 4-5 estratos de células de forma irregular hacia la superficie abaxial (Fig. 4 D). El nervio principal y los secundarios, totalmente inmersos en el mesofilo, se encuentran formados por haces vasculares colaterales cerrados, rodeados por una vaina de células parenquimáticas con escasos cloroplastos (Fig. 4 C). 
Bol. Soc. Argent. Bot. 49 (2) 2014
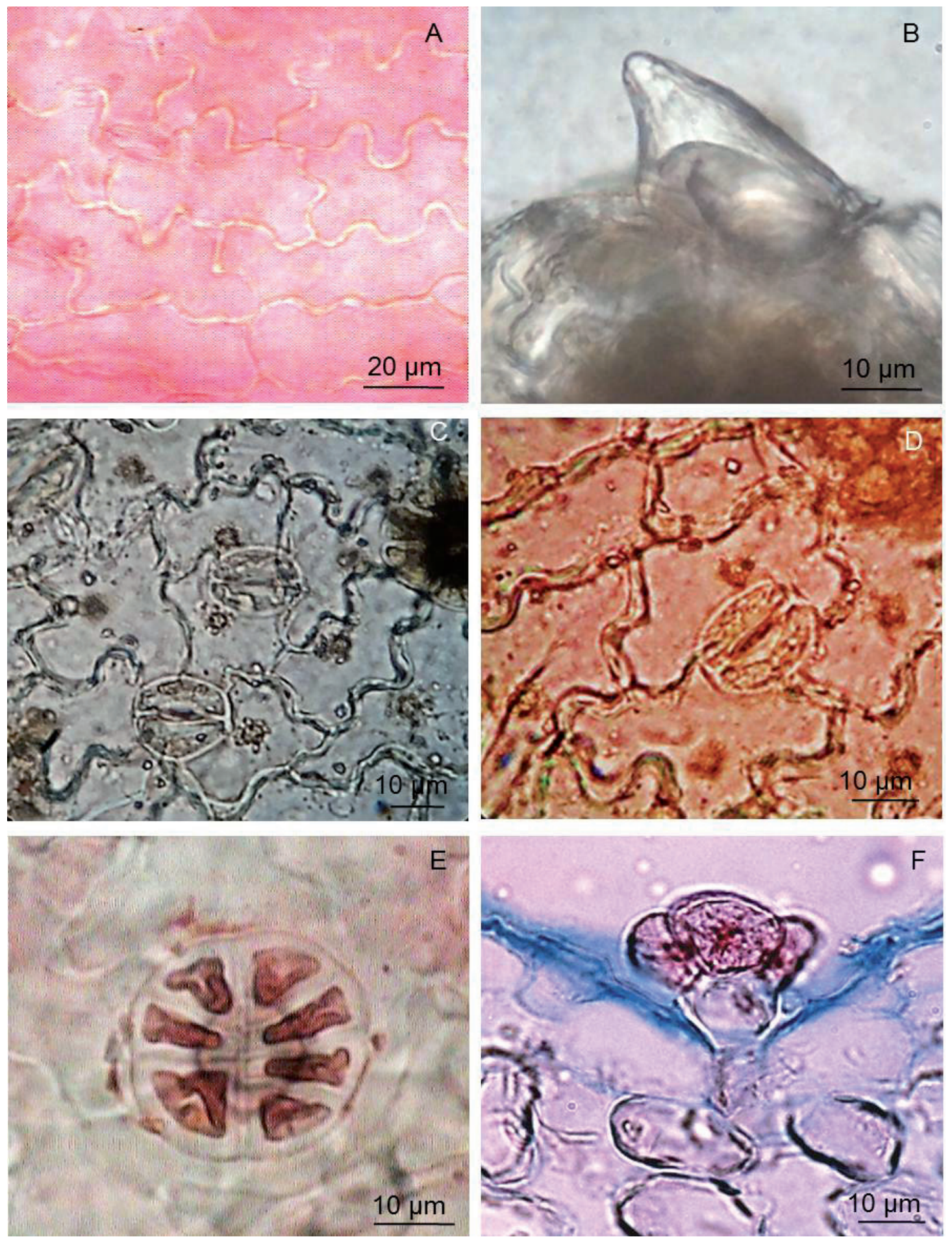

Fig. 3. Epidermis de Scoparia montevidensis. A: Células epidérmicas propiamente dichas, en vista superficial. B: Papila en margen foliar. C: Estomas anomocíticos. D: Estoma hemiparacítico. E, F: Tricoma glandular de cabeza pluricelular. E: En vista superficial. F: En corte transversal, ubicado en depresión. 

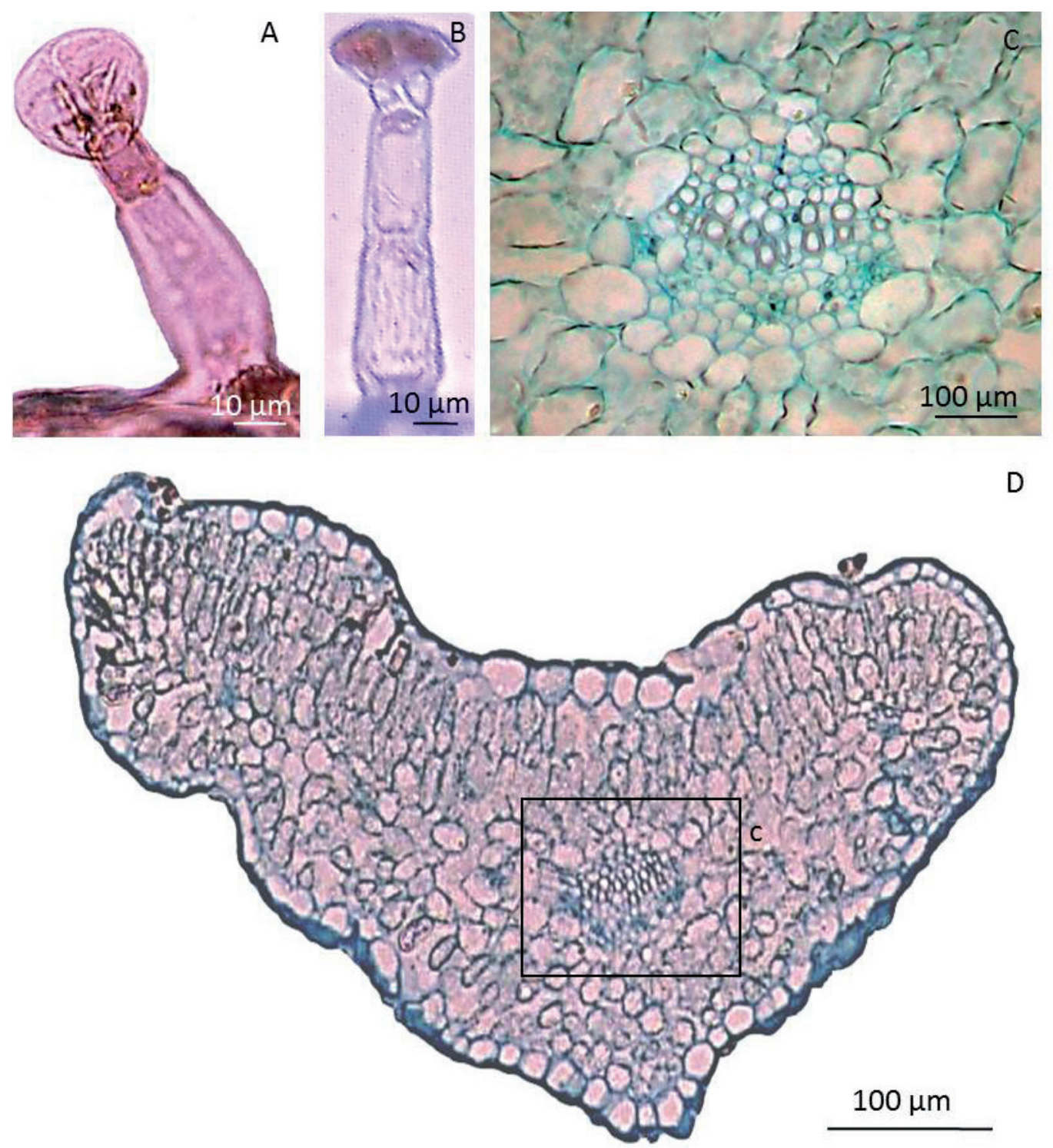

Fig. 4. Anatomía foliar de Scoparia montevidensis. A: Tricoma glandular cabeza globosa. B: Tricoma glandular cabeza elipsoide. C: Detalle de haz principal según se indica en D. D: Transcorte por segmento foliar.

Tallo. El transcorte presenta contorno hexagonal a octogonal, con 6-8 costillas y valles suaves ligeramente plano convexos o cóncavos (Fig. 5 A). El sistema dérmico está representado por una epidermis uniestrata, la cutícula es delgada y notablemente estriada con células isodiamétricas en las costillas y rectangulares en los valles, las paredes tangenciales son convexas y se observan escasos estomas, papilas (Fig. 5 B, C,
D) y numerosos tricomas, iguales a los de las hojas. El sistema fundamental está representado por una corteza caracterizada por valles con colénquima uniestrato y de tipo laminar, que alternan con costillas que presentan 3-4 estratos de parénquima colenquimatoso y cordones de fibras esclerenquimáticas (Fig. 5 B, E). En la corteza se observan 3-4 estratos de clorénquima continuos o bien dispuestos laxamente a modo 
Bol. Soc. Argent. Bot. 49 (2) 2014
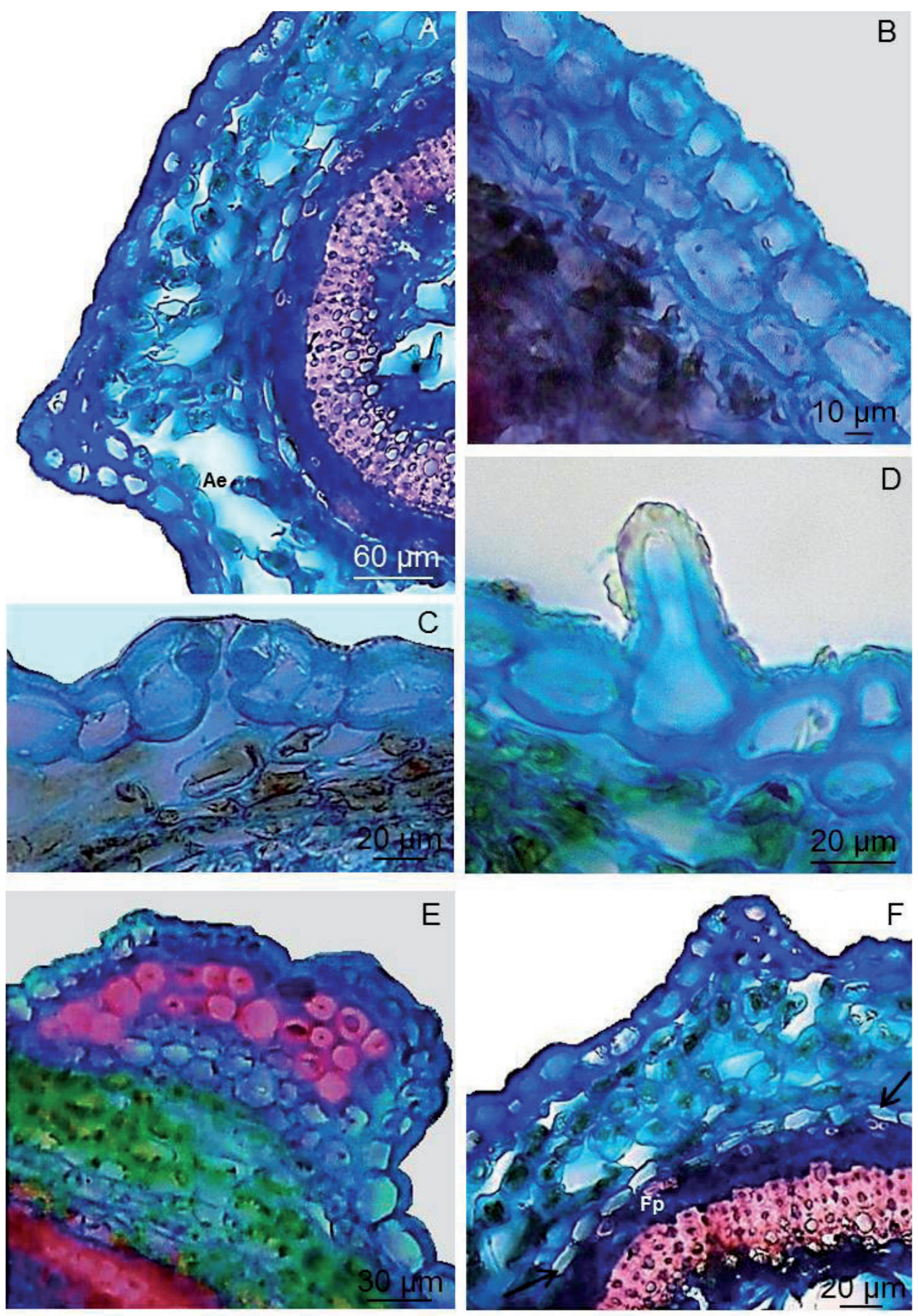

Fig. 5. Anatomía de tallo de Scoparia montevidensis. A: Transcorte mostrando sector de tallo con aerénquima $(\mathrm{Ae})$. B: Detalle de corteza con colénquima uniestrato laminar. C: Estoma en corte transversal. D: Papila en corte transversal. E: Detalle caulinar de costilla con fibras esclerenquimáticas. F: Detalle de corteza con aerénquima, obsérvense las fibras perifloemáticas ( $F p)$ y la endodermis (flechas). 
de un aerénquima, mientras que en el límite interno se diferencia una endodermis (Fig. 5 A, F). El parénquima medular posee células de contorno circular a poligonal, de paredes delgadas y en el centro se observa una laguna medular. Los tejidos de conducción forman un cilindro vascular continuo con crecimiento secundario y presentan fibras perifloemáticas (Fig. $5 \mathrm{~F}$ ).

\section{Schkuhria pinnata (Lam.) Kuntze ex Thell.}

La droga comprende el sistema caulinar cortado $(0,5 \mathrm{~cm}$ hasta $3 \mathrm{~cm})$ y triturado (menos de 0,5 $\mathrm{cm})$. Las muestras comerciales presentaron un color marrón amarillento $10 \mathrm{Y} \mathrm{R}$ (5/6) (Fig. 6 A). Se encontraron fragmentos de tallos delgados acostillados y secciones de hojas sueltas (1-2 pinatisectas con segmentos lineares) en verticilos dímeros que otorgaban a la muestra aspecto pajizo (Fig. 6 B-D). Se identificaron, además, capítulos heteromorfos, flores liguladas pistiladas y tubulosas perfectas, sueltas, (Fig. 6 E, F), y aquenios obpiramidales tetrágonos con 8 páleas ovadas, múticas o aristadas (Fig. $6 \mathrm{G}, \mathrm{H}$ ).

Hoja. La epidermis adaxial y abaxial en vista superficial, presenta sus células fundamentales más o menos isodiamétricas, con paredes anticlinales curvas en el epifilo y onduladas en el hipofilo y estomas anomocíticos (Fig. 7 A, B). El indumento es punteado-glanduloso (Fig. 6 D) con tricomas eglandulares aplicados y erectos, y glandulares de cabeza unicelular claviforme y globosa. A continuación se describen cada uno de ellos:

- Eglandulares aplicados, son verrucosos y presentan epitricopodio 1-4-celular, con células notablemente más cortas que las 1-4 células restantes del tricoma, célula apical larga y acuminada, (Fig. 7 D) y se encuentran principalmente en el pecíolo y en los márgenes foliares donde alcanzan mayor longitud.

- Eglandulares erectos o algo inclinados, son uniseriados, pluricelulares, con células de paredes lisas y contenido celular que se alargan hacia el ápice (Fig. 7 E) son más abundantes en el pecíolo.

- Glandulares con cabeza unicelular claviforme, poseen epitricopodio 3-5-celular, son verrucosos (Fig. $7 \mathrm{G}$ ) y se observan más frecuentemente en el peciolo.

- Glandulares con cabeza unicelular globosa, son peltados y se ubican en depresiones epidérmicas (Fig. 7 C, F) son muy abundantes en ambas epidermis.

La lámina en transcorte posee contorno levemente angular con depresiones que le dan aspecto foveolado (Fig. 8 A).La epidermis es uniestratificada con cutícula delgada y estriada, presenta células más o menos redondeadas y más altas sobre el haz central, las paredes tangenciales externas son rectas y gruesas y las tangenciales internas convexas (Fig. 8 B). Los estomas se encuentran a nivel, hundidos y elevados (Fig. 8 C), poseen una pequeña proyección a modo de uña en la cara externa de las células oclusivas y cámara subestomática pequeña. El mesofilo es isolateral, el parénquima en empalizada está constituido por 2-3 estratos de células columnares largas hacia ambas epidermis, es discontinuo a nivel del hacecillo principal y hacia los márgenes de la lámina hay colénquima angular (Fig. $8 \mathrm{D}$, E). El hacecillo principal es colateral, rodeado por abundante parénquima incoloro con paredes celulares engrosadas y por un estrato de parénquima colenquimatoso subyacente a la epidermis del epifilo e hipofilo, se observan, además, cuatro hacecillos secundarios totalmente inmersos en el mesofilo y rodeados de una vaina de células parenquimáticas (Fig. 8 D). Se encuentran cavidades esquizógenas relacionadas al hacecillo principal (Fig. 8 F).

Tallo. El transcorte presenta contorno hexagonal con 6 costillas y 6 valles suaves (Fig. 9 A). El sistema dérmico está formado por una epidermis uniestratificada de células pequeñas isodiamétricas, con las paredes tangenciales convexas y cutícula delgada. La epidermis posee abundantes estomas elevados (Fig. 9 B) y tricomas. Los estomas están ubicados principalmente en los valles y poseen una notoria proyección a modo de uña en la cara externa de las células oclusivas. Se observan dos tipos de tricomas glandulares, semejantes a los de la epidermis foliar: con cabeza unicelular claviforme y epitricopodio 3-4-celular, verrucosos y abundantes en las costillas (Fig. 9 C); con cabeza unicelular globosa, peltados y ubicados en depresiones de los valles del tallo. La corteza posee en la zona de las costillas 3-4 estratos de colénquima angular y en los valles, 2-3 capas de células de clorénquima, en el límite interno se destaca una endodermis de células rectangulares grandes (Fig. 9 D). En tallos 
Bol. Soc. Argent. Bot. 49 (2) 2014
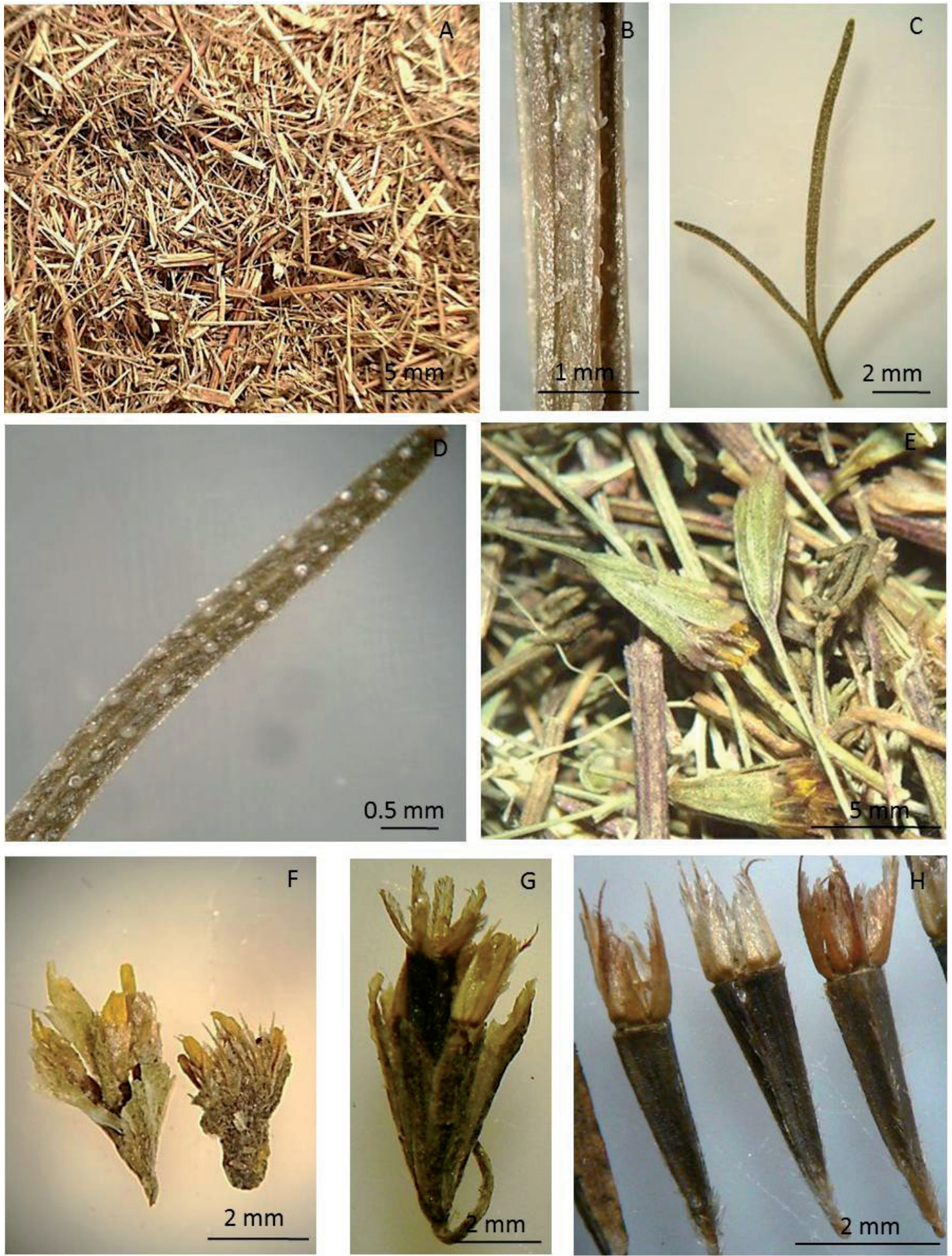

Fig. 6. Droga de Schkuhria pinnata. A: Fragmentos de droga con aspecto pajizo y color marrón amarillento. B: Fragmento de tallo delgado. C: Hoja pinatisecta. D: Segmento linear de hoja con indumento punteadoglanduloso. E: Inflorescencias desecadas. F: Flores. G: Fruto en capítulo. H: Aquenios. 


\section{L. Molinelli et al. - Calidad Botánica de las "Canchalaguas"}
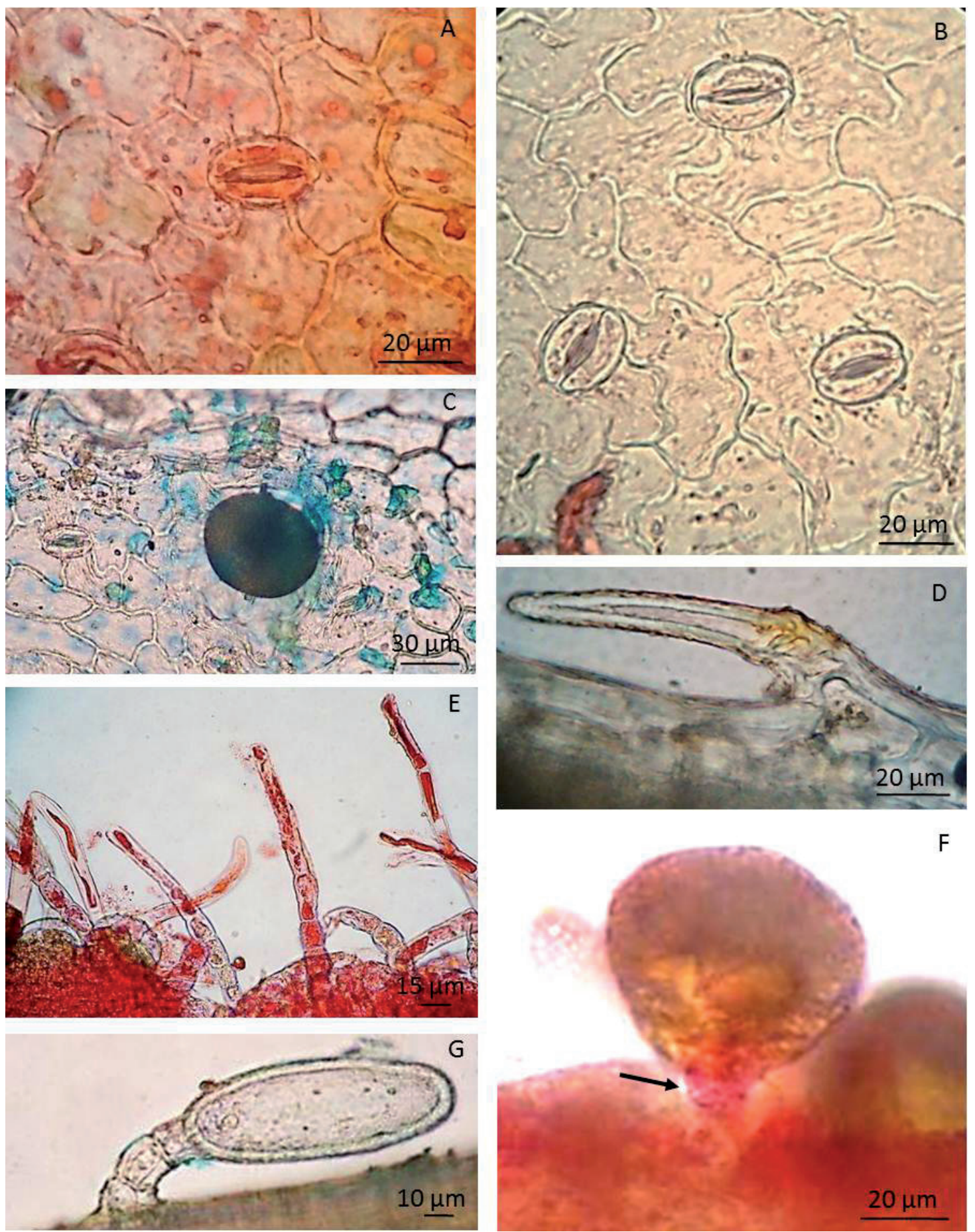

Fig. 7. Epidermis foliar de Schkuhria pinnata. A: Epidermis adaxial. B: Epidermis abaxial. C: Tricoma glandular de cabeza globosa en vista superficial. D: Tricoma eglandular con célula apical acuminada. E: Tricomas eglandulares, multicelulares con contenido celular. F: Tricoma gandular de cabeza globosa, la flecha indica el pie. G: Tricoma glandular de cabeza claviforme y epitricopodio tricelular. 
Bol. Soc. Argent. Bot. 49 (2) 2014
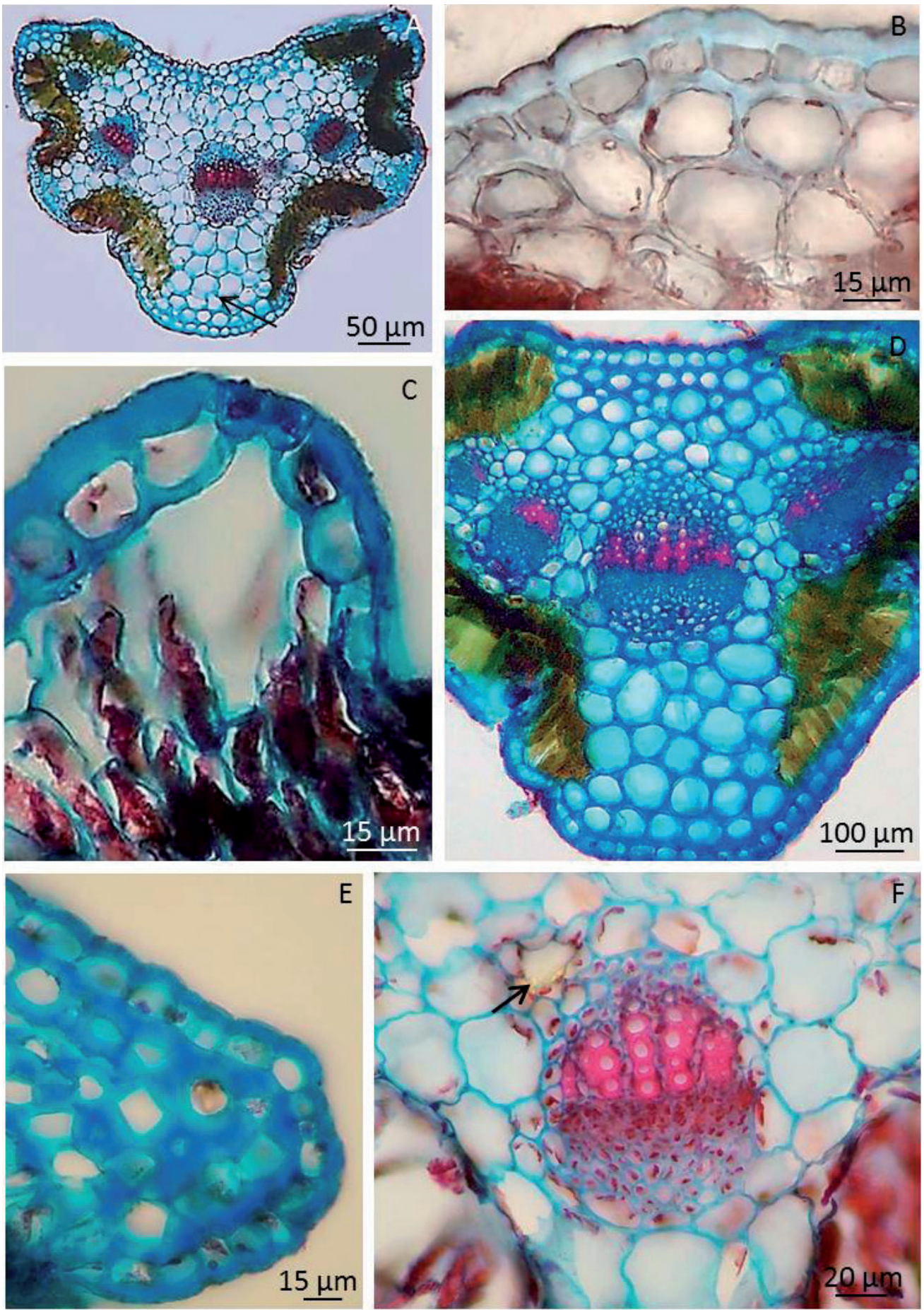

Fig. 8. Anatomía foliar de Schkuhria pinnata. A: Transcorte foliar (la flecha indica parénquima en empalizada discontinuo). B: Células epidérmicas en corte transversal. C: Estoma elevado. D: Transcorte foliar a nivel del haz principal. E: Detalle del extremo foliar. F: Corte transversal del nervio principal, la flecha señala una cavidad esquizógena. 

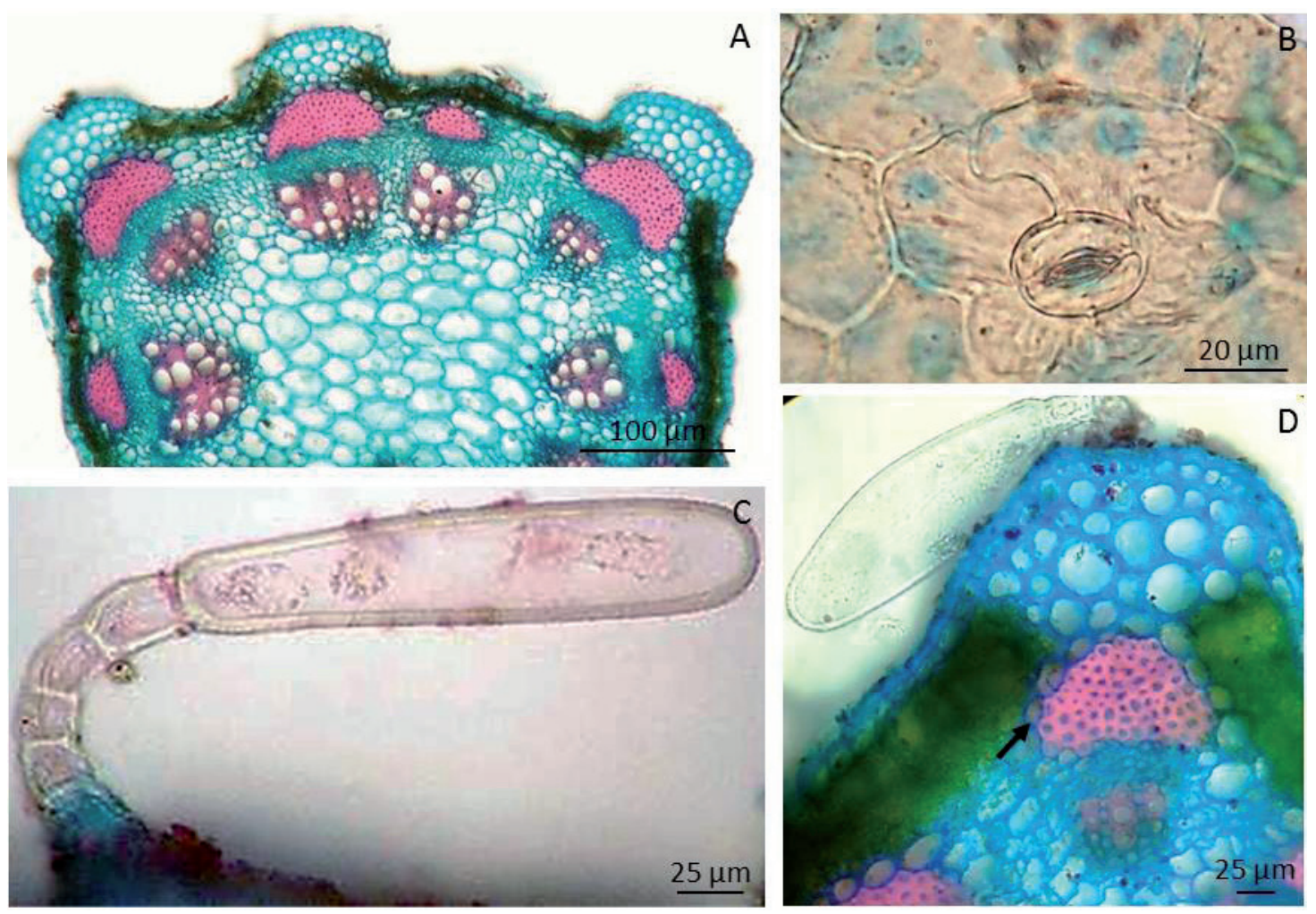

Fig. 9. Anatomía de tallo de Schkuhria pinnata. A: Corte transversal mostrando sector de tallo. B: Detalle de estoma elevado en vista superficial. C: Tricoma glandular claviforme. D: Costilla del tallo mostrando colénquima angular, la flecha indica la endodermis.

jóvenes, la médula es maciza y está constituida por células parenquimáticas, prismáticas de gran tamaño y paredes delgadas (Fig. 9 A), en tallos adultos la médula es hueca. El sistema vascular comprende haces colaterales abiertos dispuestos alrededor de una médula y separados por parénquima interfascicular formando una eustela típica, los haces vasculares poseen casquetes de fibras asociados al floema.

\section{Parthenium hysterophorus L.}

Las muestras comerciales adulteradas presentaron fragmentos de estructuras vegetativas y reproductivas de $P$. hysterophorus (Fig. $10 \mathrm{~A}$ ). Las secciones de tallos y hojas (Fig. 10 B, C), estas últimas alternas, pecioladas y bipinatisectas, exhibían un color gris oliva 5 Y (5/2), mientras que las inflorescencias, algunas fragmentadas en sus flores constitutivas, un color amarillo pálido $5 \mathrm{Y}$
(8/2) (Fig. 10 D, E) y los frutos, acompañados de dos brácteas persistentes, un color negro GLEY 1 (2.5/) (Fig. 10 F, G).

Hoja. La epidermis foliar en vista superficial, presenta las células fundamentales con paredes anticlinales rectas a curvas en el epifilo y onduladas en el hipofilo. Los estomas son anomocíticos en coincidencia con Monge (1995), y en los polos de las células oclusivas de algunos estomas se observa un engrosamiento de cutina en forma de "T": pieza T (Fig. 11 A, B). El indumento es glanduloso pubescente en el epifilo y densamente pubescente lanuginoso en el hipofilo (Fig. $10 \mathrm{C} \mathrm{y}$ $11 \mathrm{C}$ ). Se observan los siguientes tipos de tricomas eglandulares y glandulares:

- Eglandulares curvados o inclinados, son uniseriados, con la célula apical acicular y el cuerpo formado por 5-7 células esféricas con una de las paredes radiales más larga por lo que el tricoma 
Bol. Soc. Argent. Bot. 49 (2) 2014
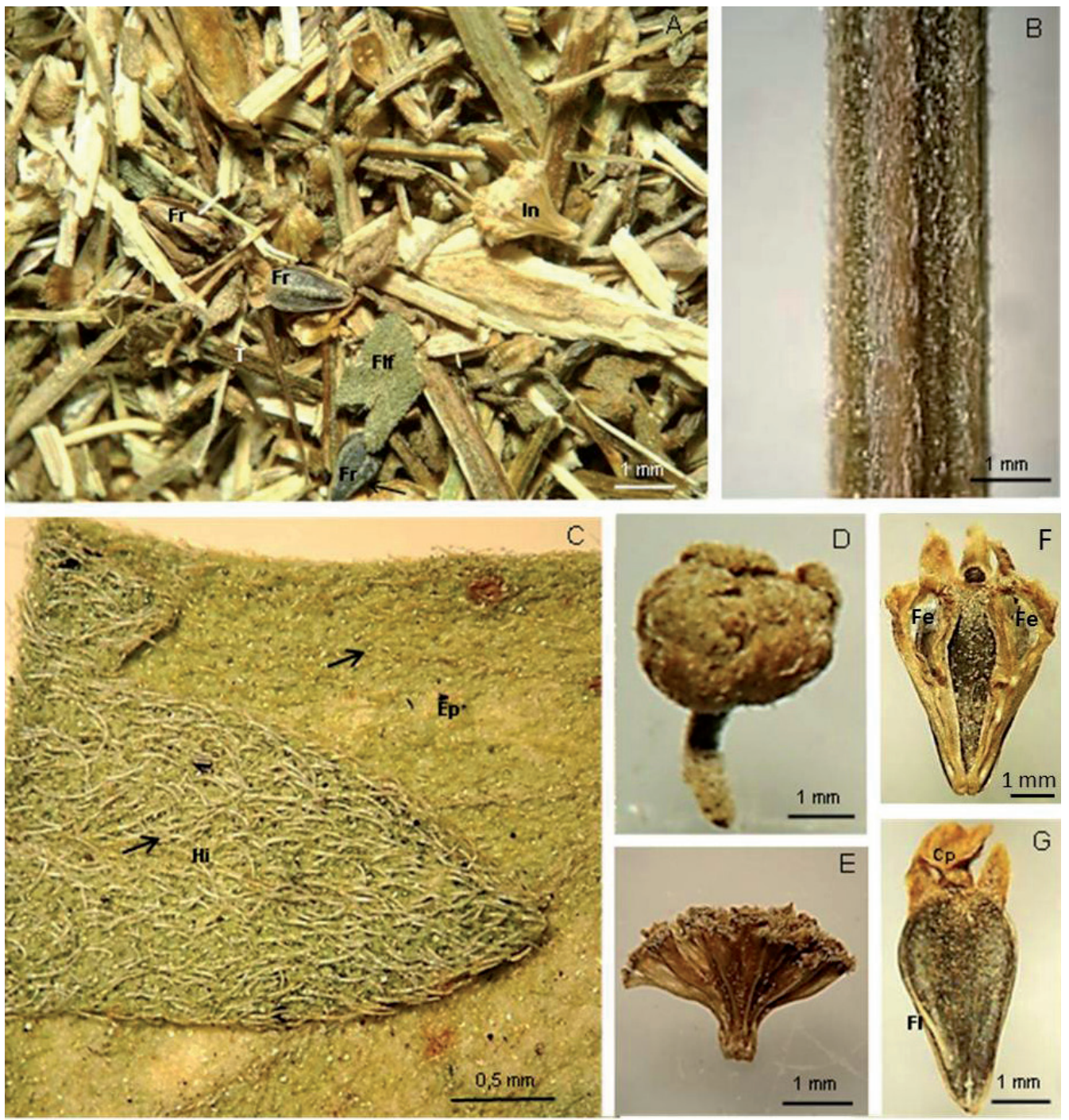

Fig. 10. Droga de "canchalagua" adulterada y estructuras de Parthenium hysterophorus. A: Muestra comercial de "canchalagua" adulterada con Parthenium hysterophorus (Fr: fruto, T: tallo, In: inflorescencia, FIf: fragmento de lámina foliar). B: Fragmento de tallos con indumento pubescente. C: Fragmento de hoja, nótese el indumento glanduloso pubescente en el epifilo (Ep) y densamente lanuginoso en el hipofilo (Hi). D: Capítulo entero. E: Flores. F: Aquenio acompañado por dos flores estaminadas (Fe). G: Aquenio negro (FI: filamento lateral, $\mathrm{Cp}$ : corola persistente).

se curva hacia la superficie del órgano. Las células poseen paredes lisas, gruesas, ocasionalmente con el lumen reducido o casi obliterado, en algunos casos se observan esferocristales en su interior (Fig. $11 \mathrm{D}, \mathrm{E})$.

- Eglandulares aplicados, uniseriados, formados por una célula apical redondeada y un cuerpo de 3-8 células que se alargan progresivamente hacia el ápice. Son verrucosos, con paredes delgadas y a menudo presentan cristales de oxalato de calcio (Fig. 11 F, G). Se encuentran rodeados radialmente por células al mismo nivel o levemente elevados sobre un cojinete uniestratificado. Son muy abundantes, especialmente en la cara abaxial.

- Eglandulares filiformes, miden 1-3 mm de long., el cuerpo es pluricelular y uni-o biseriado, 

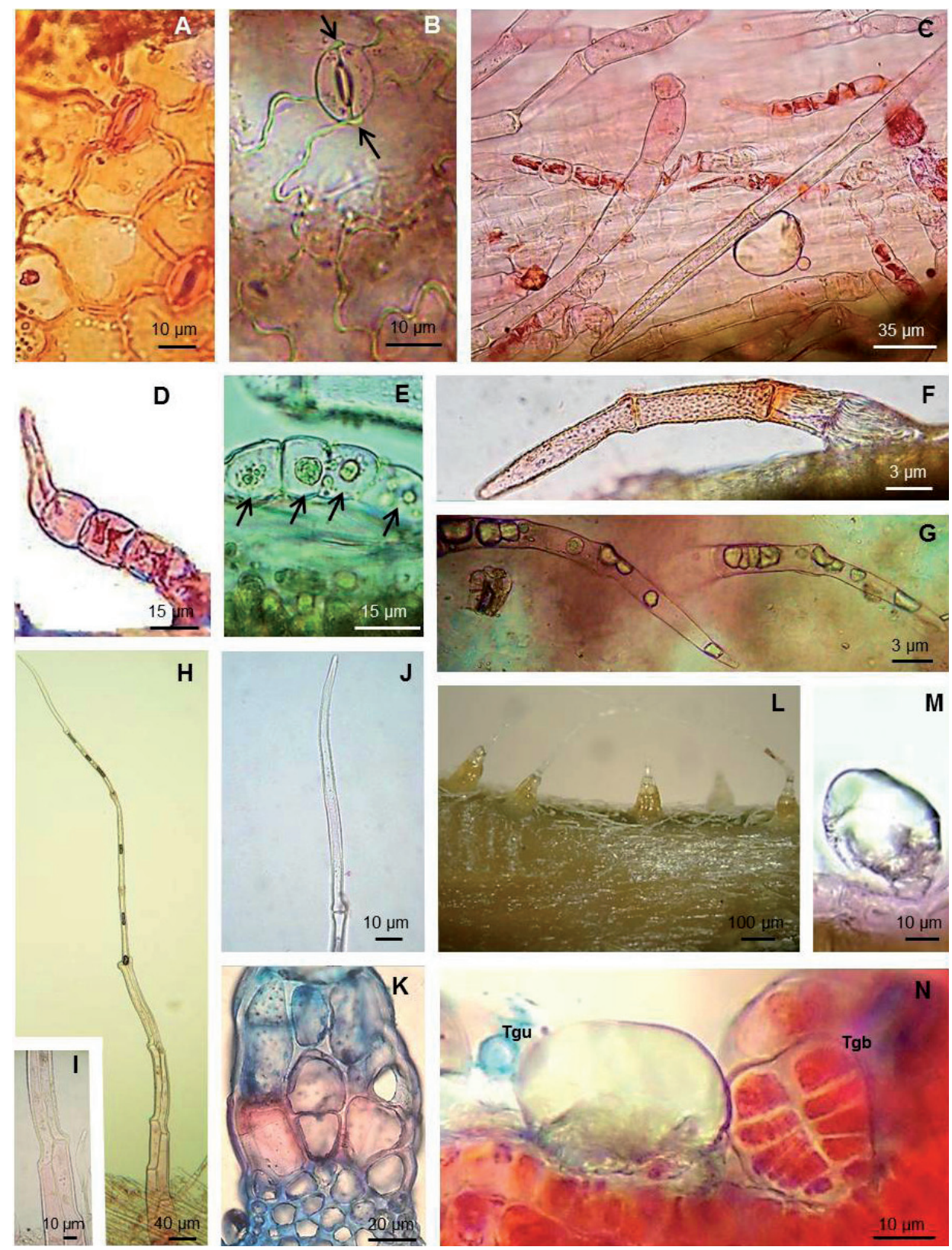

Fig. 11. Epidermis foliar de Parthenium hysterophorus. A, B: Epidermis en vista superficial del epifilo y del hipofilo respectivamente, mostrando estomas anomocíticos, las flechas indican engrosamiento de cutina en los polos del estoma anomocitíco. C: Vista general de epidermis foliar mostrando tricomas eglandulares y un tricoma glandular. D: Tricoma eglandular (obsérvense las paredes gruesas y el lumen reducido). E: Detalle de tricoma eglandular con esferocristales en las células del cuerpo (señalados con flechas). F: Tricoma eglandular aplicado verrucoso. G: Tricomas eglandulares aplicados con cristales en su interior. H: Tricoma eglandular filiforme. I-K: Detalles del tricoma eglandular filiforme (en I se observan las uniones celulares con rebordes, en $\mathrm{J}$ la célula apical y en $\mathrm{K}$ el epitricopodio). L: Vista general del indumento del pecíolo mostrando tricomas eglandulares aplicados y filiformes. M: Tricoma glandular de cabeza unicelular globosa (se observa la célula del cuello de forma trapezoidal). $\mathbf{N}$ : Tricomas glandulares de cabeza unicelular globosa (Tgu) y biseriado (Tgb). 
con células osteoladas, las proximales son más cortas que las restantes y la célula apical es larga, recta y acuminada, las uniones celulares son rectas o con dos pequeños rebordes (Fig. $11 \mathrm{H}-\mathrm{J}$ ). Están elevados considerablemente de la superficie epidérmica sobre un epitricopodio pluriestratificado de desarrollo variable, cilíndrico o lageniforme, uni o pluriseriado en la base y uni o biseriado en el ápice, con células más o menos isodiamétricas o cilíndricas, con gruesas paredes celulósicas (Fig. $11 \mathrm{~K})$. Es común que los estratos proximales del epitricopodio correspondan a colénquima angular y los distales a células parenquimáticas de paredes engrosadas. Se distribuyen en la base foliar, en los márgenes del pecíolo (Fig. 11 L) y sobre la nervadura principal del tercio inferior de la lamina foliar en la cara adaxial. Este tipo de estructuras que elevan el tricoma considerablemente y en las que intervienen estratos subepidérmicos es denominado como emergencias por Bonzani et al, (1997) para algunas verbenáceas. Estructuras semejantes, descriptas por otros autores (Botta, 1993; Di Fulvio \& Dottori, 1995; Filippa et al., 1999) en especies de verbenáceas, hidrofiláceas y plantagináceas fueron nombradas como tricomas sobre pedestal, sobre cojín o sobre epitricopodio. Por otro lado, Healey et al. (1986) denominaron "basal prolifferation" a estructuras similares en otras especies de Parthenium.

- Glandulares de cabeza unicelular globosa, con el pie constituido por una célula basal similar a las restantes células epidérmicas y la célula del cuello de forma trapezoidal (Fig. $11 \mathrm{M}, \mathrm{N}$ ). Son los más comunes y frecuentes principalmente sobre la epidermis abaxial.

- Glandulares biseriados, poseen forma subpiramidal, presentan una cabeza formada por dos series de 3-4 células en cada una y rodeada por una cutícula vesicular y un pie biseriado con un par de células basales y un cuello de 1-2 células en cada serie (Fig. $11 \mathrm{~N}$ ). En hojas jóvenes son frecuentes en ambas epidermis, mientras que en las adultas son escasos.

Ambos tipos de tricomas glandulares son característicos de la familia Asteráceas (Metcalfe \& Chalk, 1972) y en particular los tricomas glandulares biseriados son semejantes a los descriptos por Healey et al. (1986) en otras especies de Parthenium, sin embargo estos autores los describen como sésiles mientras que los encontrados en P. hysterophorus poseen pie biseriado pluricelular. Los tricomas eglandulares aplicados con célula apical redondeada y los glandulares de cabeza globosa son semejantes a los nombrados por Monge (1995) y Rodríguez et al. (1976 a) para P. hysterophorus. En este trabajo se confirma su presencia y se agregan detalles morfológicos en relación a la forma de sus células, el grosor y la naturaleza de sus paredes y el contenido celular, y además se caracterizan nuevos tricomas para esta especie. Del mismo modo Piazzano et al. (1998) mencionan la presencia de tricomas simples pluricelulares en $P$. hysterophorus, pero al no realizar una descripción detallada de los mismos, no se los puede asemejar o diferenciar con los tricomas observados en el presente trabajo.

La lámina en transcorte posee un área de resalto hacia el hipofilo en correspondencia con el nervio medio con tres sobresaliencias que coinciden con los tres haces mayores (Fig. 12 A). La epidermis uniestrata está formada por células rectangulares o isodiamétricas, con paredes tangenciales internas convexas y las externas más rectas y gruesas. La cutícula es delgada y estriada principalmente a nivel de los hacecillos (Fig. 12 B). Los estomas poseen células oclusivas a nivel o elevadas en columnas formada por 1-4 células, con cámara subestomática bien delimitada y fuertemente cutinizada que queda incluida en la elevación y se extiende brevemente hasta el clorenquima subyacente(Fig. 12 C).

El mesofilo es isolateral, constituido hacia la superficie adaxial por 1-2 estratos compactos de parénquima en empalizada con células columnares largas y hacia la superficie abaxial por 1-3 estratos de células columnares cortas aisodiamétricas que en algunos sectores adquieren una disposición más laxa (Fig. $12 \mathrm{D})$, en los bordes de la lámina el parénquima en empalizada se dispone orientado radialmente hacia la vaina del hacecillo lateral, el parénquima esponjoso es escaso.

Los hacecillos menores están rodeados por una vaina parenquimática con cloroplastos conspicuos y la distancia entre hacecillos no es mayor a cuatro células (Fig. 12 D). Estas características del mesofilo son consistentes con una estructura Kranz, y según lo enunciado por Moore et al. (1987) corresponden a un mecanismo fotosintético intermedio $\mathrm{C} 3-\mathrm{C} 4$. En el nervio mediolos hacecillos son colaterales y se encuentran rodeados de una vaina amilífera. Los hacecillos colaterales (Fig. $12 \mathrm{E}$ ) poseen hacia la cara abaxial casquetes de fibras protofloemáticas de 

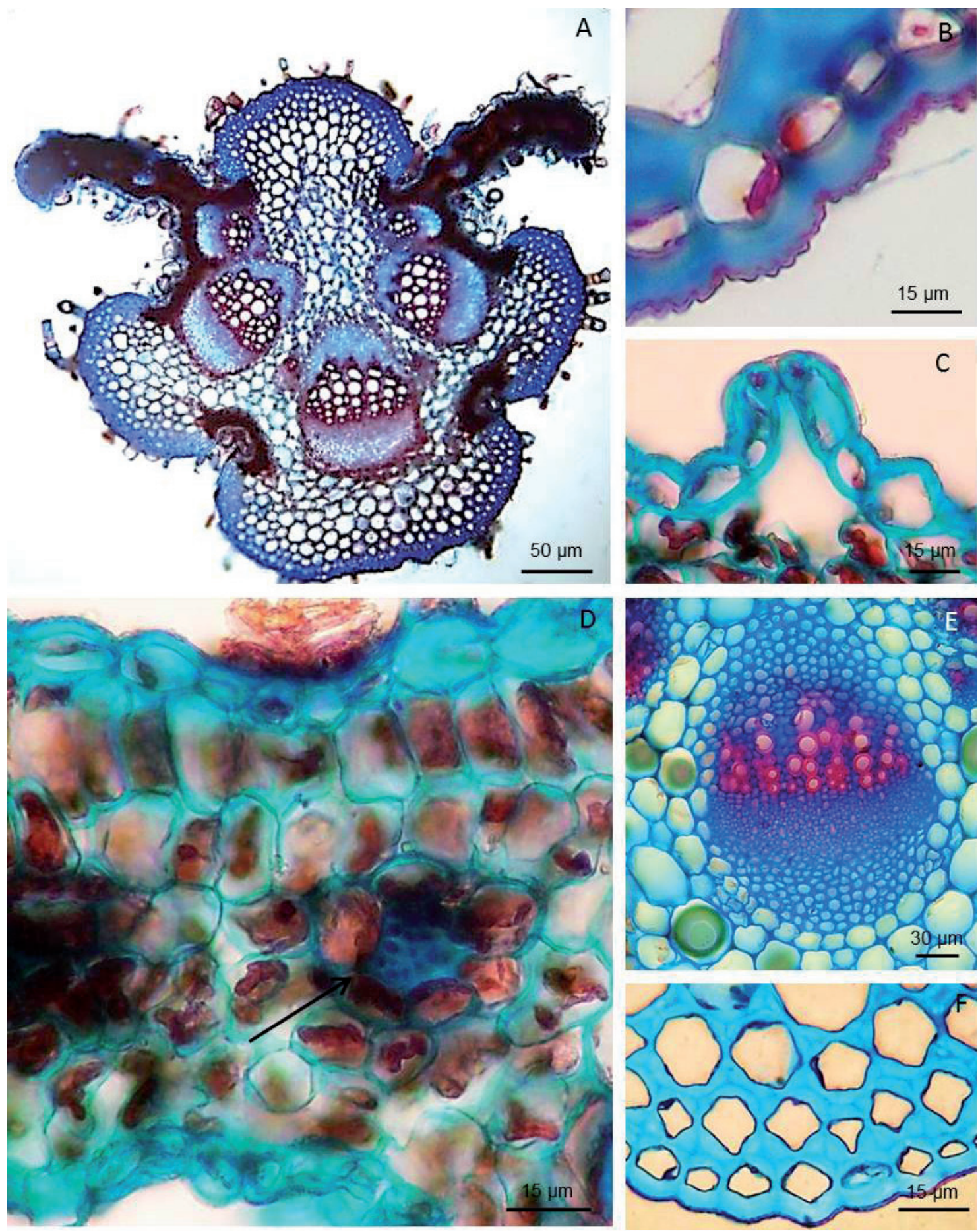

Fig. 12. Anatomía foliar de Parthenium hysterophorus. A: Transcorte foliar. B: Células epidérmicas en corte transversal mostrando cutícula estriada. C: Estoma en columna. D: Sector de lámina con mesofilo isolateral, se observa hacecillo menor con vaina Kranz (flecha). E: Haz mayor. F: Corte transversal de un sector de nervio medio, hacia la epidermis abaxial, mostrando cutícula y tejido colenquimático subepidérmico. 
paredes no lignificadas engrosadas con colénquima, y en concordancia con lo señalado por Evert (2006), su origen estaría dado por los miembros de tubo criboso infuncionales del floema primario. Hacia la cara adaxial se observan fibras del protoxilema que se originan de los miembros de vaso infuncionales incluidos en abundante parénquima xilemático que también presenta paredes engrosadas sin lignificar. Se observan hacia ambas epidermis varias capas de parénquima incoloro y 4-5 estratos de colénquima angular (Fig. $12 \mathrm{~F}$ ) hacia la epidermis adaxial y 1-2 estratos de colénquima laminar hacia la epidermis abaxial. Canales secretores esquizógenos se encuentran relacionados con los hacecillos vasculares. Si bien todas estas características del mesofilo y de los hacecillos vasculares del nervio principal coinciden con la descripciones realizadas por Piazzano et al. (1998), estos autores no mencionan las características del mesofilo correspondientes a la estructura Kranz.

Tallo. El transcorte presenta contorno hexagonal a octogonal con abundante indumento (Fig. 13 A). El sistema dérmico está representado por una epidermis uniestrata (Fig. 13 B), con células isodiamétricas en las costillas y rectangulares en los valles, las paredes tangenciales son gruesas y convexas. La cutícula es delgada y notablemente estriada. La epidermis posee estomas elevados y abundantes tricomas eglandulares y glandulares (Fig. 13 C), que responden a los caracteres ya detallados para las hojas, no se encuentran los tricomas eglandulares filiformes sobre emergencia.

El sistema fundamental está formado por una corteza caracterizada por presentar en las costillas 4-5 estratos de colénquima angular y 4-5 estratos de clorénquima en los valles. No se encontró colénquima laminar en los valles, como lo mencionan Piazzano et al. (1998). En el límite interno de la corteza se observa una endodermis. El parénquima medular posee células grandes de contorno circular a poligonal con paredes delgadas. En coincidencia con Piazzano et al. (1998) se observan canales esquizógenos pequeños cercanos a los haces vasculares (Fig. 13 D).

El sistema vascular comprende haces colaterales abiertos (Fig. 13 D, E), en discrepancia con lo descripto por Piazzano et al. (1998) quienes mencionan haces colaterales cerrados. Los haces colaterales abiertos poseen casquetes de fibras asociados al floema, están dispuestos alrededor de una médula y separados por parénquima interfascicular formando una eustela típica (Fig. $13 \mathrm{~A})$.

\section{Legitimidad de las drogas analizadas}

De las 59 muestras analizadas, 40 (Tabla 1) contenían las especies Scoparia montevidensis o Schkuhria pinnata y fueron consideradas genuinas.

En las dos muestras (Tabla 1) en las que en el rótulo de las mismas, menciona además del nombre vernáculo el nombre científico, no se encontró correspondencia entre éste último y las especies identificadas en esas drogas. Teniendo en cuenta el artículo 6 del Código Alimentario Argentino (2009), estas dos muestras se consideran como falsificaciones, ya que se encontraron las siguientes denominaciones: Sisyrinchium a la especie Scoparia montevidensis, como Sisyrinchium vaginatum a la especie Schkuhria pinnata, y como Centaurium cachanlahuen a la especie Scoparia montevidensis.

Una muestra (Tabla 1) se clasificó como falsificada y adulterada por reunir los requisitos correspondientes a dichas categorías.

En seis muestras (Tabla 1) se detectaron mezclas de las dos especies (Scoparia montevidensis y Schkuhria pinnata) y en ninguna de ellas se encontraron declarados en los rótulos los nombres de las especies que conformaban la mezcla. Esta situación evidencia que las muestras analizadas corresponden a mezclas de drogas vegetales que se están comercializando como monodrogas bajo la denominación de "canchalagua". Circunstancia también manifestada en otros estudios sobre plantas medicinales comercializadas en el noreste de Brasil (Nascimento et al., 2005).

Una de las muestras (Tabla 1) se clasificó como mezcla y adulterada (debido a que las especies halladas fueron Scoparia montevidensis, Schkuhria pinnata y Parthenium hysterophorus).

En nueve de las muestras (Tabla 1), bajo el nombre de "canchalagua", se detectaron restos vegetales de $P$. hysterophorus. No se hallaron registros bibliográficos que mencionen a esta especie de Asteraceae bajo la denominación de "canchalagua", siendo los nombres vernáculos más comúnmente empleados para nombrarla "altamisa", "falsa altamisa", "altamisa del campo", "altamisa del bordo" y "yerba de la oveja" (Ratera \& Ratera, 

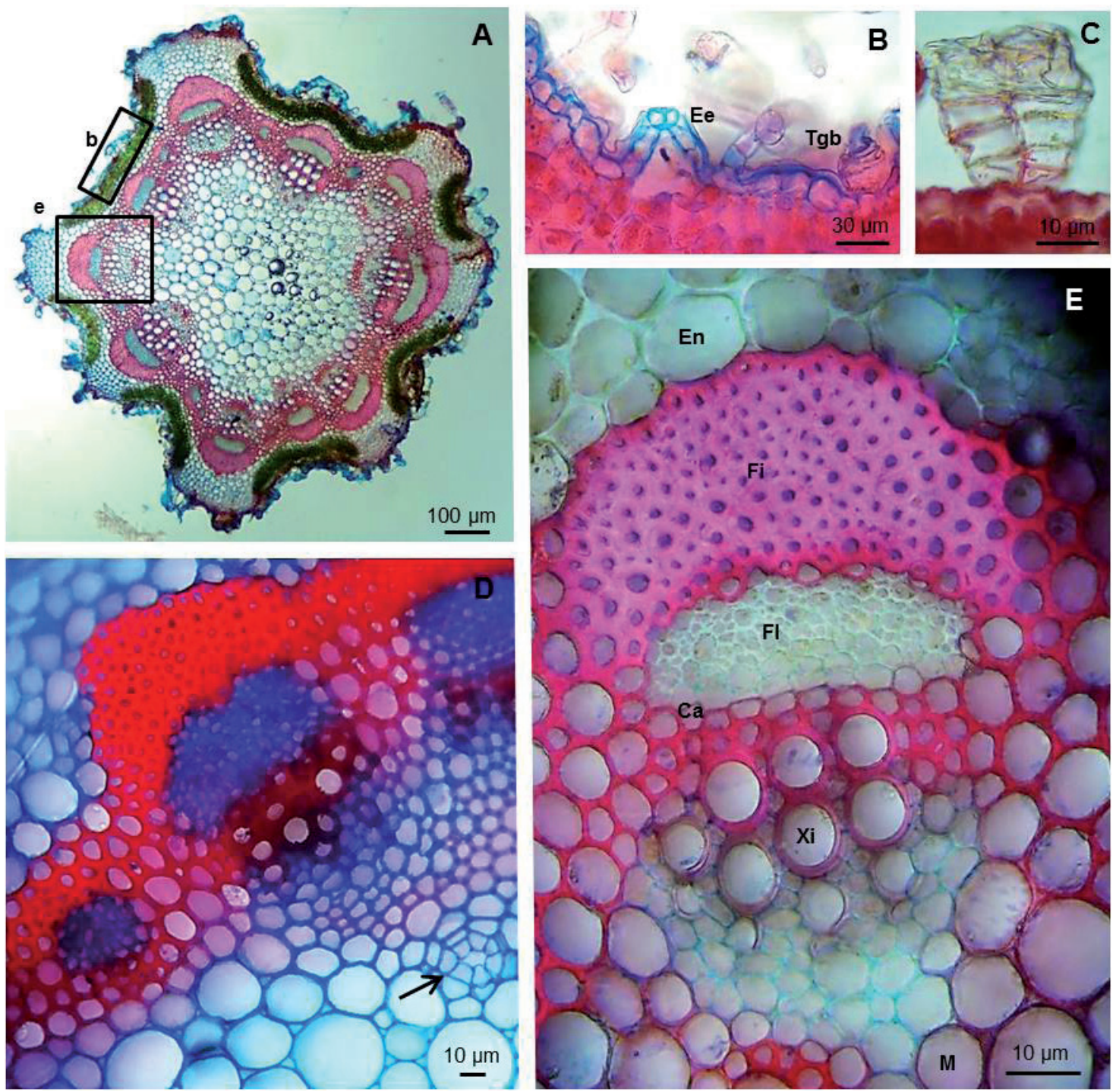

Fig. 13. Anatomía de tallo de Parthenium hysterophorus. A: Transcorte por tallo. B: Detalle de sector caulinar (valle) mostrando estoma elevado (Ee) y tricoma glandular biseriado (Tgb), según se indica en A. C: Tricoma glandular biseriado. D: Detalle de transcorte por tallo (con flecha se señala un canal esquizógeno). E: Hacecillo colateral abierto en corte transversal de zona caulinar marcada en A (Ca: cambium, En: endodermis, Fi: fibras, Fl: floema, M: médula, Xi: xilema).

1980; Marzocca, 1997; Roig, 2001; Scarpa, 2002; De la Peña \& Pensiero, 2004; Carrizo et al., 2005; Barboza et al., 2006). Es por ello que se consideraron a estas muestras adulteradas.

Para $P$. hysterophorus los usos tradicionales citados son como hepática, depurativa, antidiabética, vermífuga, antimalárica, febrífuga, analgésica, antineurálgica, hipotensiva, emoliente, antidiarreica, también se la emplea como tónico amargo y para el tratamiento de la disentería, las infecciones urinarias y respiratorias (Ratera \& Ratera, 1980; Filipov, 1997; Núñez \& Cantero, 2000; Scarpa, 2002; Barboza et al., 2006; Menseguez et al., 2007; Martínez, 2010). En relación a los constituyentes químicos, se detectaron y caracterizaron los polifenoles y flavonoides en las 
Tabla 1. Clasificación de las muestras de "canchalagua" según el grado de legitimidad.

\begin{tabular}{|lc|}
\hline \multicolumn{1}{|c}{ Legitimidad } & $\mathbf{N}^{\circ}$ de muestras \\
\hline Droga genuina & 40 \\
Droga falsificada & 2 \\
Droga falsificada y adulterada & 1 \\
Droga mezcla & 6 \\
Droga mezcla y adulterada & 1 \\
Droga adulterada & 9 \\
\hline
\end{tabular}

hojas de P. hysterophorus y también se confirmó su actividad gastroprotectora (Shen et al., 1976; Bucciarelli et al., 2007). En varios trabajos se estudiaron las lactonas sesquiterpénicas presentes en P. hysterophorus (Rodríguez et al., 1976 b; Wickham et al., 1980; De la Fuente et al., 1997; 2000; Piazzano et al., 1998). También se citó esta especie como tóxica para el ganado y aunque es la causa más frecuente de la dermatitis alérgica de contacto en la India (Narasimhan et al., 1984), no se registraron casos de dermatitis causada por P. hysterophorus en América del Sur (Lakshmi \& Srinivas, 2012).

Tabla 2. Caracteres diagnósticos de flor, fruto y hoja de Scoparia montevidensis, Schkuhria pinnata y Parthenium hysterophorus.

\begin{tabular}{|c|c|c|}
\hline Especie & Scoparia montevidensis & Parthenium hysterophorus \\
\hline \multicolumn{3}{|c|}{ Caracteres morfológicos } \\
\hline Flor & $\begin{array}{l}\text { Solitaria, perfecta, con } \\
\text { pedúnculo glanduloso. }\end{array}$ & $\begin{array}{ll}\text { En capítulos completos o En capítulos completos o } & \text { fragmentados, flores dimorfas, las } \\
\text { fragmentados, flores dimorfas, } & \text { del margen cortamente liguladas, } \\
\text { una pistilada con corola ligulada } & \text { pistiladas, con } 2 \text { filamentos } \\
\text { y el resto perfectas con corola } & \begin{array}{l}\text { que las unen a flores tubulosas } \\
\text { tubulosas. } \\
\text { estaminadas. }\end{array}\end{array}$ \\
\hline Fruto & $\begin{array}{l}\text { Cápsula con cáliz } \\
\text { persistente y pedúnculo } \\
\text { glanduloso-pubescente. }\end{array}$ & $\begin{array}{ll}\text { Aquenio obpiramidal, tetrágono } & \text { Aquenio obovoide, negro, con } 2 \\
\text { con } 8 \text { páleas ovadas, múticas o o } & \text { dilataciones membranáceas en su } \\
\text { parte superior, a veces acompañado } \\
\text { aristadas. } & \text { de } 2 \text { flores estaminadas. }\end{array}$ \\
\hline \multirow{3}{*}{ Hoja } & Verticiladas. & Verticiladas. \\
\hline & $\begin{array}{l}\text { Polimorfas: lanceoladas } \\
\text { con profundas incisiones. }\end{array}$ & $\begin{array}{l}\text { Pinatisectas, con segmentos Bipinatisectas. } \\
\text { lineal-filiformes. }\end{array}$ \\
\hline & $\begin{array}{l}\text { Indumento glanduloso- } \\
\text { pubescente con papilas. }\end{array}$ & $\begin{array}{l}\text { Indumento eglanduloso y Indumento pubescente, } \\
\text { punteado-glanduloso. }\end{array}$ \\
\hline \multicolumn{3}{|c|}{ Caracteres anatómicos } \\
\hline \multirow{5}{*}{ Tricomas } & $\begin{array}{l}\text { Glandular con pie unicelular } \\
\text { corto, cabeza uni- a pluricelular. }\end{array}$ & $\begin{array}{l}\text { Eglandular, aplicado, con Eglandular, curvados o inclinados, } \\
\text { epitricopodio 1-4-celular, célula } \\
\text { apical acuminada, verrucoso. }\end{array}$ \\
\hline & $\begin{array}{l}\text { Glandular con pie bi- a } \\
\text { pluricelular largo, cabeza } \\
\text { bicelular. }\end{array}$ & $\begin{array}{l}\text { Eglandular, erecto o inclinado, Eglandular aplicado, célula apical } \\
\text { pluricelulares, paredes lisas, } \\
\text { con contenido celular. }\end{array}$ \\
\hline & & $\begin{array}{l}\text { Glandular de cabeza } 1 \text {-celular Eglandular filiforme, } 1-3 \mathrm{~mm} \text { de } \\
\text { claviforme. } \\
\text { long., con epitricopodio multiseriado. }\end{array}$ \\
\hline & & $\begin{array}{l}\text { Glandular de cabeza unicelular Glandular de cabeza unicelular } \\
\text { globosa, peltado, ubicado en globosa. } \\
\text { depresiones. }\end{array}$ \\
\hline & & $\begin{array}{l}\text { Glandular biseriado de forma } \\
\text { subpiramidal. }\end{array}$ \\
\hline \multirow[b]{2}{*}{ Mesofilo } & Dorsiventral. & Isolateral. \\
\hline & $\begin{array}{l}\text { Hacecillos colaterales, rodeados } \\
\text { por una vaina de células } \\
\text { parenquimáticas incoloras. }\end{array}$ & $\begin{array}{l}\text { Hacecillos colaterales, rodeado } \\
\text { por abundante parénquima Hacecillos menores con vaina } \\
\text { incoloro con paredes Kranz. } \\
\text { engrosadas. }\end{array}$ \\
\hline
\end{tabular}


El hallazgo de $P$. hysterophorus como especie adulterante en las muestras de "canchalagua" y los antecedentes que citan la presencia de sustancias tóxicas en esta especie, evidencian el riesgo que presenta el consumo de estas drogas para la salud (Spegazzini \& Najera, 1984).

\section{Conclusiones}

Se confirma que Scoparia montevidensis y Schkuhria pinnata son comercializadas como drogas bajo el nombre vernáculo de "canchalagua" en la ciudad de Córdoba y en localidades serranas de los Departamentos Santa María y Calamuchita. Una de las principales contribuciones de este estudio, es la descripción de los caracteres morfo-anatómicos de las estructuras vegetativas y reproductivas que permiten identificar a Scoparia montevidensis, Schkuhria pinnata y Parthenium hysterophorus. Las diferencias encontradas a nivel de la morfología de flor, fruto y hoja, permiten una primera aproximación para identificar las especies, mediante la observación con microscopio estereoscópico. En el caso que flores y frutos estén ausentes, o si la droga vegetal se encuentra muy triturada, las características anatómicas diagnósticas que permiten identificar los taxones son los tricomas de hojas y de tallos y la estructura del mesofilo. Los caracteres morfo-anatómicos diagnósticos presentados en forma comparativa (Tabla 2), resultan de gran utilidad para los directores técnicos de los establecimientos elaboradores o fraccionadores, responsables de garantizar la identidad del material botánico empleado como materia prima, así como para las autoridades sanitarias, a cuyo cargo están los controles de calidad botánico de las drogas comercializadas con fines medicinales.

En relación al análisis de legitimidad de las drogas comercializadas como "canchalagua" se advierte la presencia de muestras falsificadas, mezcla de especies y muestras adulteradas. Es importante señalar que por primera vez se cita a Parthenium hysterophorus como especie adulterante de Schkuhria pinnata.

\section{Agradecimientos}

Al Ministerio de Ciencia y Tecnología de la Provincia de Córdoba por el apoyo económico brindado.

\section{Bibliografía}

ALONSO, J. \& C. DESMARCHELIER. 2006. Plantas medicinales autóctonas de la Argentina. Bases científicas para su aplicación en atención primaria de salud. Ed. Fitociencia, Buenos Aires.

ARENAS, P. M. 2006. La columna de: Patricia Arenas. Etnobotánica en áreas urbanas. Bol. Latinoam. Caribe Plant. Med. Aromat. 5: 95.

ARIAS TOLEDO, B. 2009. Diversidad de usos, prácticas de recolección y diferencias según género y edad en el uso de plantas medicinales en Córdoba, Argentina. Bol. Latinoam. Caribe Plant. Med. Aromat. 8: 389401.

BALICK, M. J., F. KRONENBERG, A. L. OSOSKI, M. REIFF, A. FUGH-BERMAN, B. O' CONNOR, M. ROBLE, P. LOHR \& D. ATHA. 2000. Medicinal plants used by Latino healers for women's health conditions in New York City. Econ. Bot. 54: 344-357.

BARBOZA, G. E., J. J. CANTERO, C. O. NÚÑEZ \& L. ARIZA ESPINAR (eds.). 2006. Flora medicinal de la Provincia de Córdoba (Argentina). Museo Botánico Córdoba. Gráficamente ediciones, Córdoba. Argentina.

BARBOZA, G. E., J. J. CANTERO, C. NÚÑEZ, A. PACCIARONI \& L. ARIZA ESPINAR. 2009. Medicinal plants: A general review and a phytochemical and ethnopharmacological screening of the native Argentine Flora. Kurtziana 34: 7-365.

BONZANI, N. E., E. M. FILIPPA \& G. E. BARBOZA. 1997. Particularidades epidérmicas en algunas especies de Verbenaceae. An. Inst. Biol. Univ. Nac. Autón.Méx., Ser. Bot. 68: 47-56.

BOTTA, S. M. 1993. Notas en el género Glandularia (Verbenaceae: Verbenoideae): 3. Estudio taxonómico de las especies patagónicas. Parodiana 8: 9-36.

BOTTA, S. M. \& A. L. CABRERA. 1993. Scrophulariaceae. En: CABRERA, A. L. (ed.), Fl. Prov. Jujuy, República Argentina 13: 155-226. Colecc. Ci. Inst. Nac. Tecnol. Agropec., Buenos Aires.

BUCCIARELLI, A., M. M. MANCINI \& M. SKLIAR. 2007. Propiedades gastroprotectoras de plantas medicinales. Estudios fitoquímicos y farmacológicos. Revista de la Asociación Médica de Bahía Blanca 17: 3-9.

BUSSMANN, R. W., S. DOUGLAS, D. P. DIAZ \& Y. BAROCIO. 2008a. Peruvian plants canchalagua (Schkuhria pinnata (Lam.) Kuntze), hercampuri (Gentianella alborosea (Gilg.) Fabris), and corpus way (Gentianella bicolor (Wed.) J. Pringle) prove to be effective in the treatment of acne. Arnaldoa 15: 149-152.

BUSSMANN, R. W., D. SHARON, F. A. PÉREZ, D. P. DIAZ, T. FORD, T. RASHEED, Y. BAROCIO \& 
R. SILVA. 2008b. Antibacterial activity of northernperuvian medicinal plants. Arnaldoa 15: 127-148.

CABRERA, A. L. 1974. Compositae. En: BURKART, A. (ed.), Fl. Il. Entre Ríos (Argentina) 6: 106-554. Colecc. Ci. Inst. Nac. Tecnol. Agropec., Buenos Aires.

CARRIZO, E., M. O. PALACIO \& L. D. ROIC. 2005. Uso medicinal de algunas especies nativas en Santiago del Estero (República Argentina). Dominguezia 21: 25-32.

CÓDIGO ALIMENTARIO ARGENTINO. 2009. Disponible en: http//: http://www.anmat.gov.ar/ codigoa/caa1.htm [Acceso: 9 abril 2013].

CORREA, R. F. 2003. El complejo de las "canchalaguas" enArgentina: génesis, conformaciónyethnobotánica. Resumen de Tesis Doctoral. Universidad Nacional de La Plata, La Plata, Argentina. Disponible en: http:/www.bfa.fcnym.unlp.edu.ar/bfa/bases/tesis/ pdf/0794_Tesis.pdf [Acceso: 29 marzo 2013].

CREUS, C. 1986. Falsificación de documentos en general. Ed. Astrea, Buenos Aires.

CROOM, E. M. 1983. Documenting and evaluating herbal remedies. Econ. Bot. 37: 13-27.

CUASSOLO, F., A. LADIO \& C. EZCURRA. 2009. Aspectos de la comercialización y control de calidad de las plantas medicinales más vendidas en una comunidad urbana del NO de la Patagonia Argentina. Bol. Latinoam. Caribe Plant. Med. Aromat. 9: 166-176.

D’ AMBROGIO DE ARGÜESO, A. 1986. Manual de técnicas en histología vegetal. Ed. Hemisferio Sur, Buenos Aires.

DE LA FUENTE, J. R., L. NOVARA, S. R. ALARCON, O. J. DIAZ, M. L. URIBURU \& V. E. SOSA. 1997. Chemotaxonomy of Parthenium: P. hysterophorus-P. glomeratum. Phytochemistry 45: 1185-1188.

DE LA FUENTE, J. R., M. L. URIBURU, G. BURTON \& V. E. SOSA. 2000. Sesquiterpene lactone variability in Parthenium hysterophorus L. Phytochemistry 55: 769-772.

DE LA PEÑA, M. R. \& J. F. PENSIERO. 2004. Plantas argentinas. Catálogo de nombres comunes. Ed. L.O.L.A., Buenos Aires.

DEL VitTO, L. A., E. M. PETENATti \& M. E. PETENATTI. 1997. Recursos herbolarios de San Luis (República Argentina). Primera parte: plantas nativas. Multequina 6: 49-66.

DI FULVIO, T. E. \& N. DOTTORI. 1995. Contribución al conocimiento de Tricomas y emergencias en Hydrophyllaceae. Clasificación y consideraciones taxonómicas. Kurtziana 24: 19-64.

EVERT, R. F. 2006. Esau Anatomía vegetal. Meristemas, células y tejidos de las plantas: su estructura, función y desarrollo. $3^{\circ}$ ed. Ed. Omega, Barcelona.

FARMACOPEA NACIONAL ARGENTINA. 1978. $6^{\circ}$ ed. Codex S.A., Buenos Aires.
FILIPOV, A. 1997. La farmacopea natural en los sistemas terapéuticos de los indígenas Pilagá. Parodiana 10: 35-74.

FILIPPA, E., G. E. BARBOZA, M. C. LUJÁN \& L. ARIZA ESPINAR. 1999. Anatomía foliar de las especies centro-argentinas de Plantago (Plantaginaceae). Darwiniana 37: 1-13.

GADANO, A., A. GURNI \& M. A. CARBALlO. 2004. Screening genotóxico de hierbas medicinales utilizadas en la medicina tradicional argentina. Acta Toxicol. Argent. 12: 2-8.

GANZER, U. \& J. JAKUPOVIC. 1990. Schkuhripinnatolides, unusual sesquiterpene lactones from Schkuhria pinnata. Phytochemistry 29: 535-539.

GONZÁLEZ-TEJERO, M. R. \& M. CASARESPORCEL. 1996. La anatomía vegetal como método de identificación en etnobotánica. Monograf. Jard. Bot. Córdoba 3: 33-37.

GUPTA, M. P. Ed. 1995. 270 Plantas medicinales iberoamericanas. Ed. CYTED-SECAB, Bogotá, Colombia.

HEALEY, P. L., I. J. MEHTA \& K. E. WESTERLING. 1986. Leaf trichomes of some Parthenium species. Amer. J. Bot. 73: 1093-1099.

HURRELL, J. A., E. A. ULIBARRI, P. M. ARENAS \& M. L. POCHETTINO. 2011. Plantas de herboristería. Plantas medicinales que se comercializan en heboristerías de la Ciudad de Buenos Aires. Ed. L.O.L.A., Buenos Aires.

LAKSHMI, C. \& C. R. SRINIVAS. 2012. Parthenium the terminator: An update. Indian Dermatol Online J. 3: 89-100.

LEÓN, A., B. M. REYES, M. I. CHÁVEZ, R. A. TOSCANO \& G. DELGADO. 2009. Sesquiterpene lactones, acyl phenyl propanoids and other constituents from Schkuhria pinnata var. wislizeni. Antioxidant evaluation. J. Mex. Chem. Soc. 53: 193-200.

LUJÁN, M. C. \& G. E. BARBOZA. 2008. Control de calidad botánico e higiénico-sanitario de muestras comerciales usadas como droga cruda en Argentina. Arnaldoa 15: 109-125.

LUJÁN, M. C., G. E. BARBOZA, S. WELER DE SERRA \& L. ARIZA ESPINAR. 2000. Control de calidad en dos helechos medicinales y su inserción en el mercado local. Stud. Bot. 19: 75-94.

MARTÍNEZ, G. J. 2005. Recolección y comercialización de plantas medicinales en el departamento Santa María, Provincia de Córdoba, Argentina. Acta Farm. Bonaerense 24: 575-584.

MARTÍNEZ, G. J. 2010. Las plantas en la medicinal tradicional de las sierras de Córdoba. Un recorrido por la cultura campesina de Paravachasca $y$ Calamuchita. Ed. Del Copista, Córdoba, Argentina. 
MARZOCCA, A. 1997. Vademécum de malezas medicinales de la Argentina. Indígenas y exóticas. Orientación Gráfica Editora SRL, Buenos Aires.

MENDIONDO, M. E., L. R. A. DE ISRAILEV \& P. SEELIGMANN. 1990. Schkuhria pinnata (Lam.) O.K., Compositae. Estudio de sus flavonoides florales. Lilloa 37: 81-82.

MENSEGUEZ P., L. GALETTO \& A. M. ANTON. 2007. El uso de plantas medicinales en la población de El Puesto (Córdoba, Argentina). Kurtziana 33: 89-102.

METCALFE, C. R. \& L. CHALK. 1972. Anatomy of the Dicotyledons: leaves, stem and wood in relation to taxonomy with notes on economic uses. Vol. 1-2. Clarendon Press, Oxford.

METCALFE, C. R. \& L. CHALK. 1979. Anatomy of the Dicotyledons. Vol. 1. $2^{\circ}$ ed. Clarendon Press, Oxford.

METCALFE, C. R. \& L. CHALK.1989. Anatomy of the Dicotyledons Vol. 2. $2^{\circ}$ ed. Clarendon Press, Oxford.

MITRA, S. K. \& R. KANNAN. 2007. A note on unintentional adulterations in Ayurvedic herbs. Ethnobotanical Leaflets 11: 11-15.

MONGE, S. 1995. Características epidérmicas de dicotiledóneas encontradas en las dietas de herbívoros de la Reserva de la Biósfera de Ñacuñán (Santa Rosa, Mendoza). Multequina 4: 47-57.

MOORE, B. D., V. R. FRANCESCHI, S. H. CHENG, J. WU, \& M. S. B. KU. 1987. Photosynthetic characteristics of the $\mathrm{C}(3)-\mathrm{C}(4)$ intermediate Parthenium hysterophorus. Plant Physiol. 85: 978983.

MUNSELL, A. H. 2000. Munsell soil color charts. Revised washable edition. Ed. Gretagmacbeth, New Windsor, New York.

MUÑOZ, V., M. SAUVAIN, G. BOURDY, S. ARRÁZOLA, J. CALLAPA, G. RUIZ, J. CHOQUE \& E. DEHARO. 2000. A search for natural bioactive compounds in Bolivia through a multidisciplinary approach. Part III. Evaluation of the antimalarial activity of plants used by Alteños Indians. $J$ Ethnopharmacol. 71: 123-131.

NARASIMHAN, T. R., B. S. KESHAVA MURTHY, N. HARINDRANATH \& P. V. SUBBA RAO. 1984. Characterization of a toxin from Parthenium hysterophorus and its mode of excretion in animals. J. Biosci. 6: 729-738.

NASCIMENTO, J. E., E. U. LACERDA, V. T. NASCIMENTO, J. G. MELO, B. S. ALVES, L. G. M. SILVA, M. A. RAMOS, C. S. A. LIMA, U. P. ALBUQUERQUE \& E. L. C. AMORIM. 2005. Produtos à base de plantas medicinais comercializados em Pernambuco - Nordeste do Brasil. Acta Farm. Bonaerense 24: 113-122.

NUÑEZ, R. C. 1975. Tratado de derecho penal. Tomo 4. Lerner, Buenos Aires.
NÚÑEZ, C. \& J. J. CANTERO. 2000. Las plantas medicinales del sur de la provincia de Córdoba. Ed. Fundación Universidad Nacional de Río Cuarto, Córdoba, Argentina.

ORGANIZACIÓN MUNDIAL DE LA SALUD. 2003. Resolución WHA 56.31. 56 Asamblea Mundial de la Salud. OMS, Ginebra.

PACCIARONI, A., V. E. SOSA, L. ARIZA ESPINAR \& J. C. OBERTI. 1995. Sesquiterpene lactones from Schkuhria pinnata. Phytochemistry 39: 127-131.

PETENATTI, E. M. \& L. ARIZA ESPINAR. 1997. Asteraceae. Tribu VI. Helenieae. En HUNZIKER, A. T. (ed.), Flora Fanerogámica Argentina 45: 3-35.

PIAZZANO, M., G. BERNARDELLO, L. NOVARA, S. ALARCÓN, J. DE LA FUENTE \& M. HADID. 1998. Evaluación de los límites específicos entre Parthenium hysterophorus y P. glomeratum (Asteraceae-Ambrosiinae): evidencias morfológicas, anatómicas, cromosomáticas y fitoquímicas. Anal. Jardin Bot. Madrid, 56: 65-76.

POCHETTINO, M. L., P. M. ARENAS, D. SÁNCHEZ \& R. CORREA. 2008. Conocimiento botánico tradicional, circulación comercial y consumo de plantas medicinales en áreas urbanas de Argentina. Bol. Latinoam. Caribe Plant. Med. Aromat.7: 141148.

RATERA, E. L. \& M. O. RATERA. 1980. Plantas de la flora argentina empleadas en medicina popular. Ed. Hemisferio Sur, Buenos Aires.

RODRÍGUEZ, E., M. O. DILLON, T .J. MABRY, J. C. MITCHELL \& G. H. N. TOWERS. 1976 a. Dermatologically active sesquiterpene lactones in trichomes of Parthenium hysterophorus L. (Compositae). Experientia 32: 236-237.

RODRÍGUEZ, E., G. H. N. TOWERS \& J. C. MITCHELL.1976b. Biological activities of sesquiterpene lactones. Phytochemistry 15: 15731580 .

ROIG, F. A. 2001. Flora medicinal mendocina. Las plantas medicinales y aromáticas de la provincia de Mendoza (Argentina). Aborígenes, exóticas espontáneas o naturalizadas y cultivadas. Ed. EDIUNC, Mendoza, Argentina.

SCARPA, G. F. 2002. Plantas empleadas contra trastornos digestivos en la medicina tradicional criolla del chaco noroccidental. Dominguezia 18: 36-50.

SCHULZ, A. G. 1997. Algunas plantas usuales del nordeste argentino. Parodiana 10: 211-241.

SHEN, M. C., E. RODRÍGUEZ, K. KERR \& T. J. MABRY. 1976. Flavonoids of four species of Parthenium (Compositae). Phytochemistry 15:10451047.

SPEGAZZINI, E. D. \& M. T. NAJERA. 1984. Etnofarmacobotánica de los "Ajenjos" de la medicina popular argentina. Datos morfológicos 
Bol. Soc. Argent. Bot. 49 (2) 2014

para su reconocimiento. Acta Farm. Bonaerense 3: 153-160

TOURSARKISSIAN, M. 1980. Plantas medicinales de la Argentina. Sus nombres botánicos, vulgares, usos y distribución geográfica. Ed. Hemisferio Sur, Buenos Aires.

TYLER, V. E., L. R. BRADY \& J. E. ROBBERS. 1979. Farmacognosia. $2^{\circ}$ ed. Ed. El Ateneo, Buenos Aires.

VIGNALE, N. D. 2007. Identificación micrográfica de plantas medicinales andinas y su importancia en el control de calidad. Especial IX Simposio Argentino y XII Simposio Latinoamericano de Farmacobotánica. Conferencias.Bol. Latinoam. Caribe Plant. Med. Aromat. 6: 168.

WICKHAM, K., E. RODRIGUEZ \& J. ARDITTI. 1980. Comparative phytochemistry of Parthenium hysterophorus L. (Compositae) tissue cultures. Bot. Gaz. 141: 435-439.
ZAMPINI, I. C., N. CUDMANI \& M. I. ISLA. 2007. Actividad antimicrobiana de plantas medicinales argentinas sobre bacterias antibiótico-resistentes. Acta Bioquím. Clín. Latinoam. 41: 385-393.

ZARDINI, E. M. 1984. Etnobotánica de compuesta argentina con especial referencia a su uso farmacológico (Segunda Parte). Acta Farm. Bonaerense 3: 169-194.

Recibido el 24 de mayo de 2013, aceptado el 6 de noviembre de 2013. 